\title{
Supplement of \\ Toward closure between predicted and observed particle viscosity over a wide range temperature and relative humidity
}

Sabin Kasparoglu ${ }^{1}$, Ying $\mathrm{Li}^{2}$, Manabu Shiraiwa ${ }^{2}$, and Markus Petters ${ }^{1}$

${ }^{1}$ NC State University,Department of Marine, Earth, and Atmospheric Sciences, Raleigh, NC, 27695-8208

${ }^{2}$ University of California, Irvine, Department of Chemistry, Irvine, CA, 92625, USA

Correspondence: Markus Petters (mdpetter@ncsu.edu)

Contents

1 Gordon Taylor Mixing rules $\quad 2$

2 The variability of kappa with temperature and water activity. $\quad 2$

3 Cold-Temperature DCIC experiments $\quad 4$

$\begin{array}{llll}5 & 4 & \text { Summary of Experiments } & \mathbf{7}\end{array}$

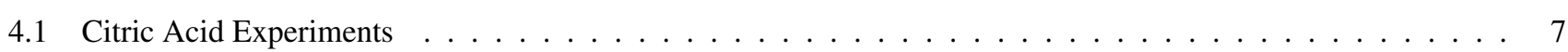

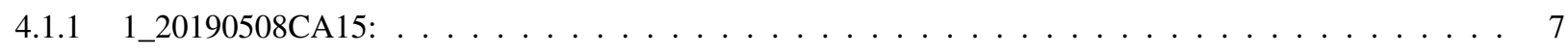

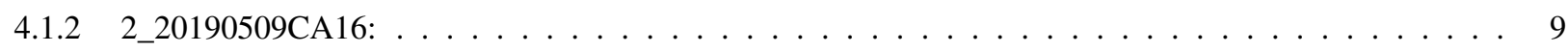

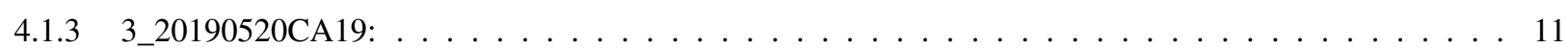

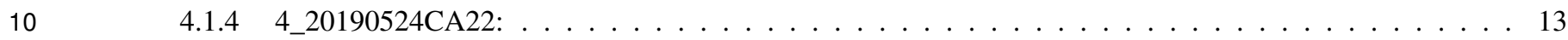

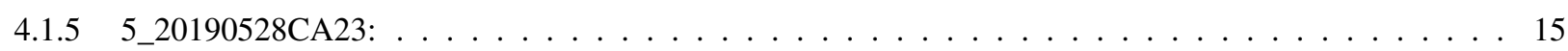

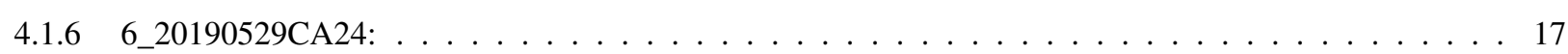

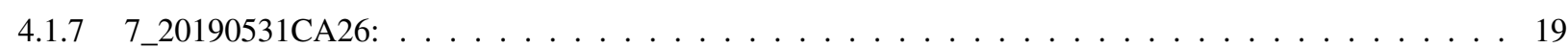

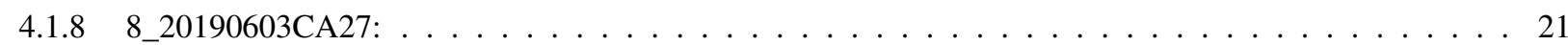

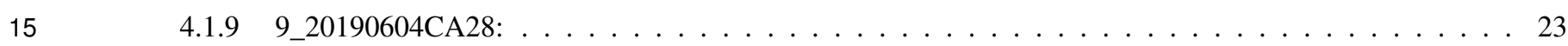

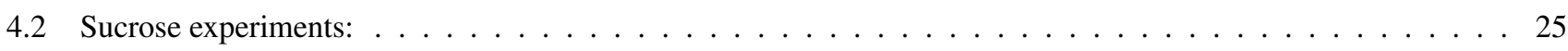

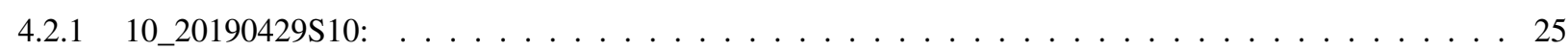

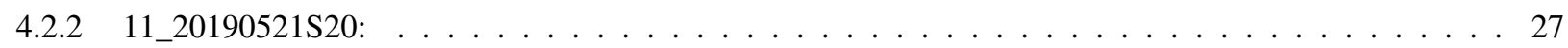

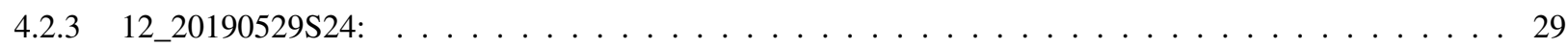


Figure S1 summarizes the glass transition literature data for sucrose and citric acid together with the fitted Gordon-Taylor mixing rule.

\section{(a) Sucrose}

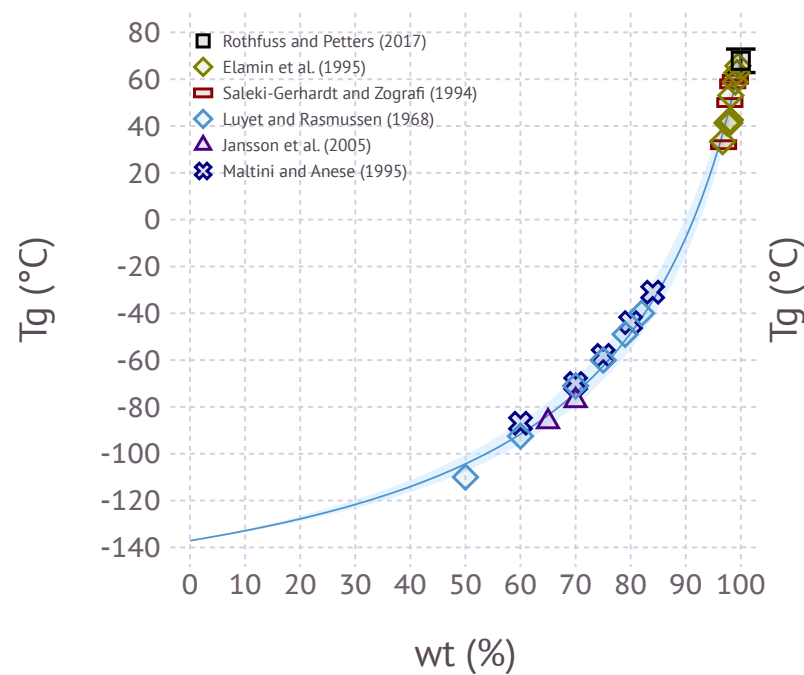

(a) Citric Acid

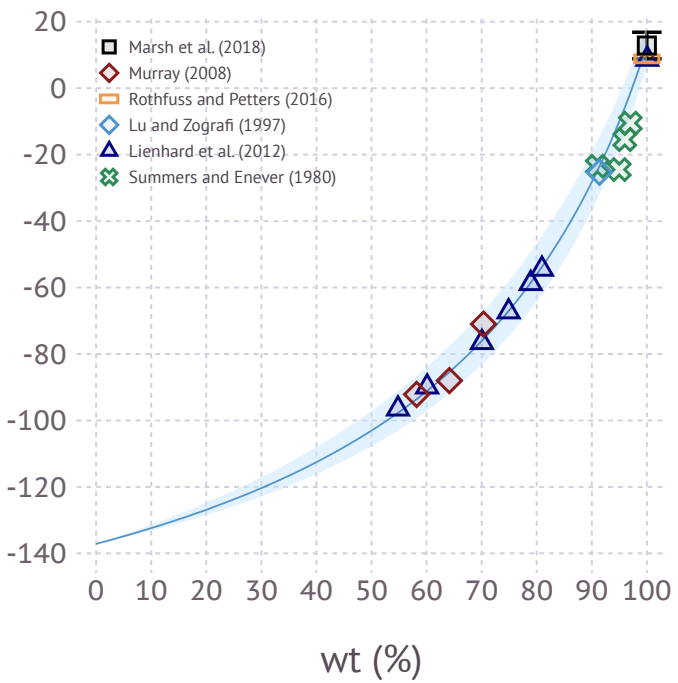

Figure S1. State diagram of the sucrose-water system (left) and citric acid water system (right) as a function of the solute weight fraction. Data are from: (Elamin et al., 1995; Jansson et al., 2005; Lienhard et al., 2012; Lu and Zografi, 1997; Maltini and Anese, 1995; Marsh et al., 2018; Murray, 2008; Rothfuss and Petters, 2016, 2017; Saleki-Gerhardt and Zografi, 1994; Summers and Enever, 1980). The blue solid line and shaded area is the estimation from Gordon-Taylor mixing rule (Gordon and Taylor, 1952) (Eq. 3, main text), assuming $k_{G T}=5.25 \pm 0.5$ (sucrose-water) and $k_{G T}=3.4 \pm 0.5$ (citric acid water).

\section{The variability of kappa with temperature and water activity.}

Zobrist et al. (2008) and Lienhard et al. (2012) report parameterizations of water activity as a function of temperature and

solute weight fraction for sucrose and citric acid, respectively. For sucrose:

$a_{w}\left(w_{s}, T\right)=\frac{1+a_{1} w_{s}}{1+a_{2} w_{s}+a_{3} w_{s}^{2}}+\left(T-T^{\Theta}\right)\left(a_{4} w_{s}+a_{5} w_{s}^{2}+a_{6} w_{s}^{3}+a_{7} w_{s}^{4}\right)$

where $w_{s}$ is the solute weight fraction, $T$ is the absolute temperature and $T^{\Theta}=298.15 \mathrm{~K}$. For citric acid:

$$
\begin{gathered}
a_{w}\left(w_{s}, T\right)=\frac{1-w_{s}}{1+q w_{s}+r w_{s}^{2}} \\
q=a_{1}+a_{2} T+a_{2} T^{2} \\
r=a_{4}+a_{5} T+a_{6} T^{2}
\end{gathered}
$$


Table S1. Coefficients to compute water activity for sucrose and citric acid: ${ }^{(a)}$ Zobrist et al. (2008) and ${ }^{(b)}$ Lienhard et al. (2012).

\begin{tabular}{cccccccc}
\hline Compounds & $a_{1}$ & $a_{2}$ & $a_{3}$ & $a_{4}$ & $a_{5}$ & $a_{6}$ & $a_{7}$ \\
\hline sucrose $^{(a)}$ & -1.00 & -1.013 & 0.1704 & 0.001688 & -0.005151 & 0.009607 & -0.006142 \\
citric acid $^{(b)}$ & -3.16761 & 0.01939 & $-4.02725 e-5$ & 6.59108 & -0.05294 & $1.06028 e-4$ &
\end{tabular}

(a) Sucrose

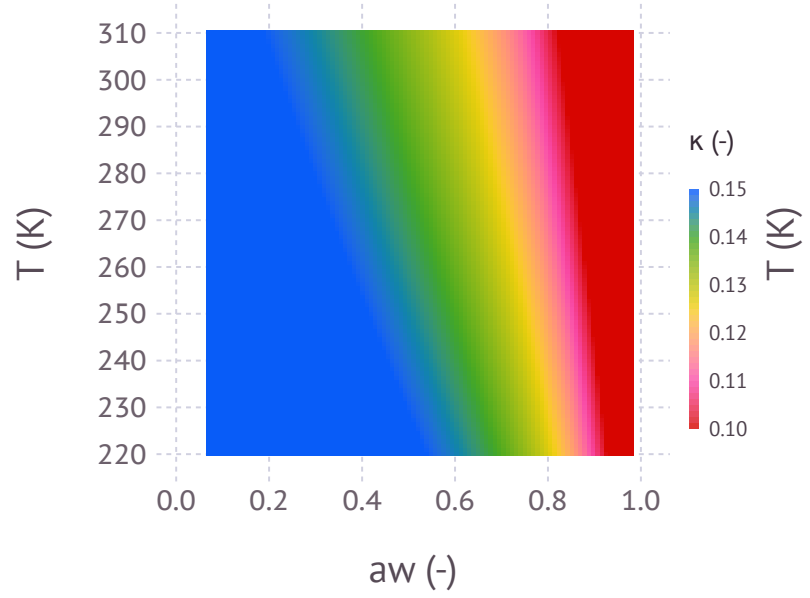

(b) Citric acid

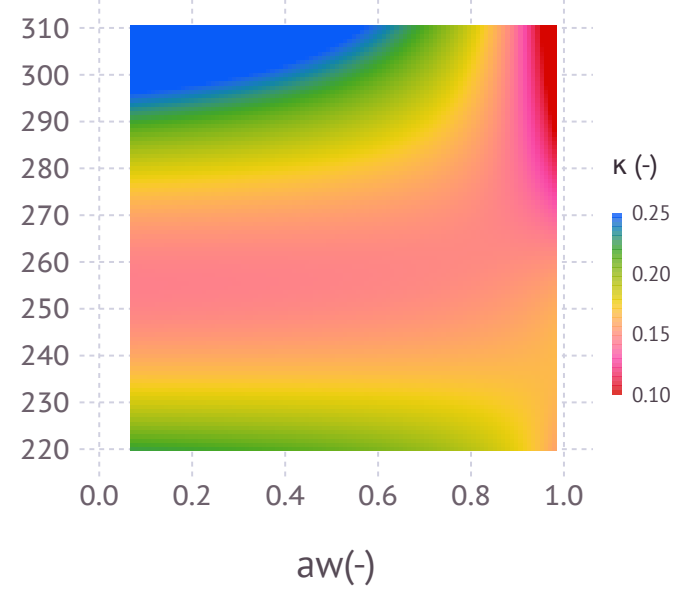

Figure S2. The variability of kappa with temperature and water activity for (a) sucrose and (b) citric acid.

Coefficients of these parameterizations are summarized in Table S1. The phase diagram model in the main text requires input of $\kappa_{m}\left(a_{w}, T\right)$, which is computed via

$\kappa=\left(w_{s}^{-1}-1\right)\left(\frac{1-a_{w}}{a_{w}}\right)$

which is transcendental due to the dependence of $w_{s}$ on $a_{w}$. For convenience the inversion from $a_{w}\left(w_{s}, T\right)$ to $\kappa_{m}\left(a_{w}, T\right)$ is performed numerically. The resulting dependence of $\kappa_{m}$ on water activity (or relative humidity) and temperature is visualized in Figure S2. Figure S2 shows that there is a relatively weak composition and temperature dependence of $\kappa_{m}$ for sucrose and 35 a strong dependence of $\kappa_{m}$ on temperature for citric acid. 


\section{Cold-Temperature DCIC experiments}

The cold temperature DCIC experiments and associated calibrations are described by example of experiment 11_20190521S20 (Sucrose, this experiment is also given in supplement part of 3.2.2 11_20190521S20). The experimental system is described in the main text. During a cold-temperature experiment, the freezer is set to some initial temperature. The particle streams are composed of probe particle DMA 1 (polyethylene particles) and test particle DMA 2 (either sucrose or citric acid) are concentrations are ramped up until a coagulation peak is observed. The particles are dried upstream to ensure that the dewpoint temperature of the combined polyethylene/solute mixture is well below the coldest temperature within the entire system. Once the system is at the desired initial condition, the temperature of the conditioner is decreased through an automatic ramp function.

45 The upstream drying system can produce variable RH, depending on the temperature of the cold trap, the state of the silica gel drier, and the optional use of a humidifier. Therefore the total moisture content of the particles leaving the coalescence chamber varies with time and can either increase or decrease.

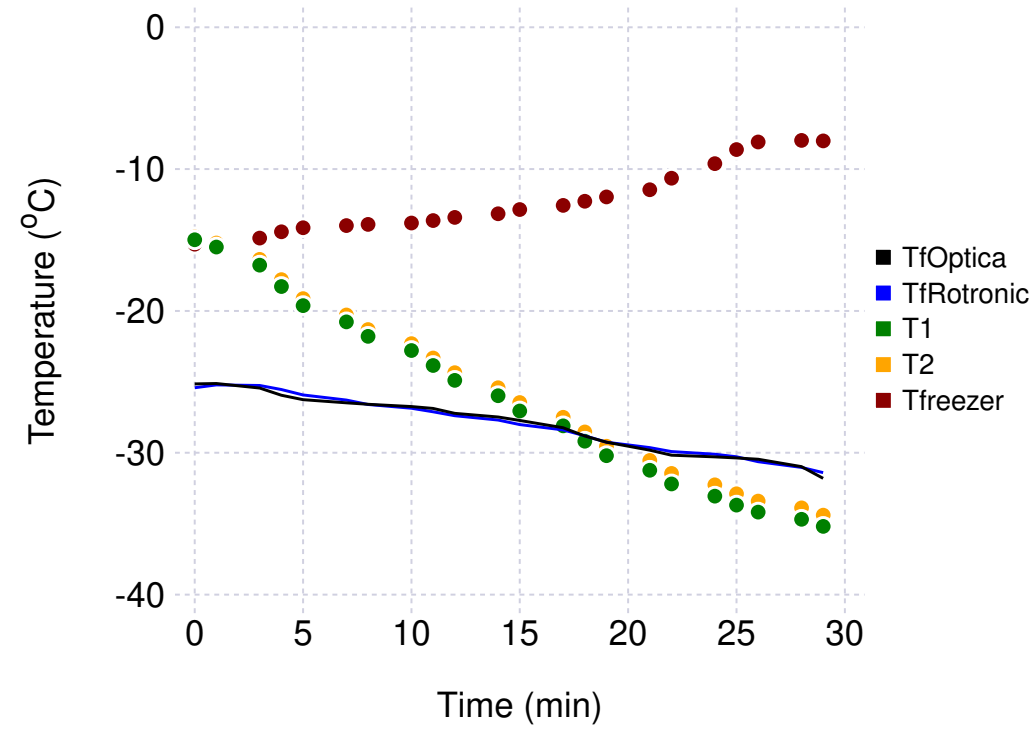

Figure S3. Variation of critical absolute temperatures and frost point temperatures over the duration of the experiment. The dots (T1, T2 and Tfreezer) correspond to the average temperature during an SMPS scan. The solid lines (TdOptica, TfRotronic) are $1 \mathrm{~Hz}$ measurements of dew point temperatures of the experiments.

Figure S3 shows the time evolution of temperatures and frost point temperatures at various points in the system from ramp start $(t=0)$ until the end of the ramp. Temperature T1 and T2 monitor the temperature inside the coalescence chamber, which is controlled by two thermoelectric coolers (TE-Technology CP-200). The heat rejected by the thermoelectric coolers is dissipated into the freezer, which causes it to warm during the experiment.At the exit of the coalescence chamber the air is split between the SMPS for size distribution measurement and humidity measurements. Humidity is measured by a Rotronic capacitance 
probe, which senses RH and it's internal temperature. From these the frost point is calculated. Air exiting the Rotronic is passed to a frost-point/dew-point sensor (Optica).

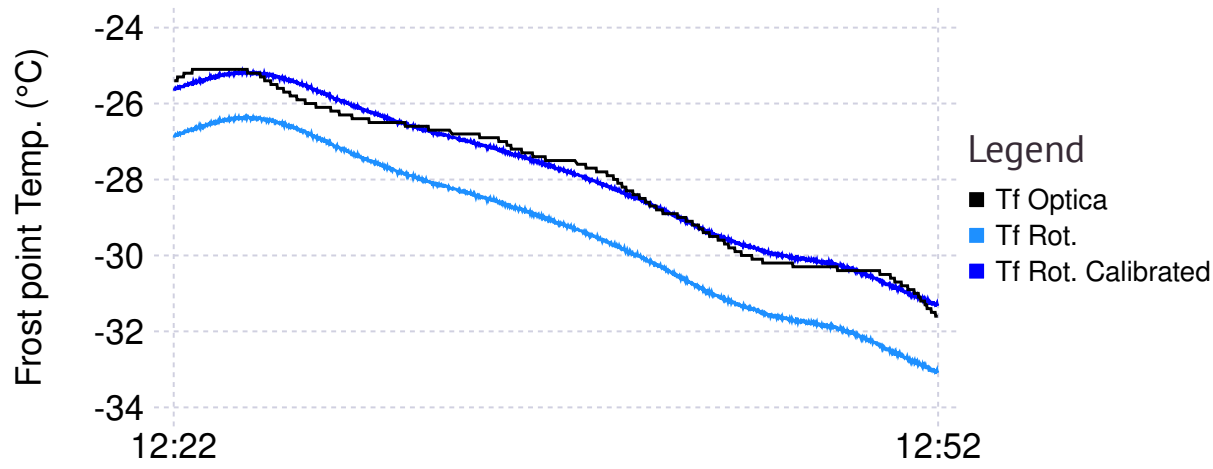

Time (HH:MM)
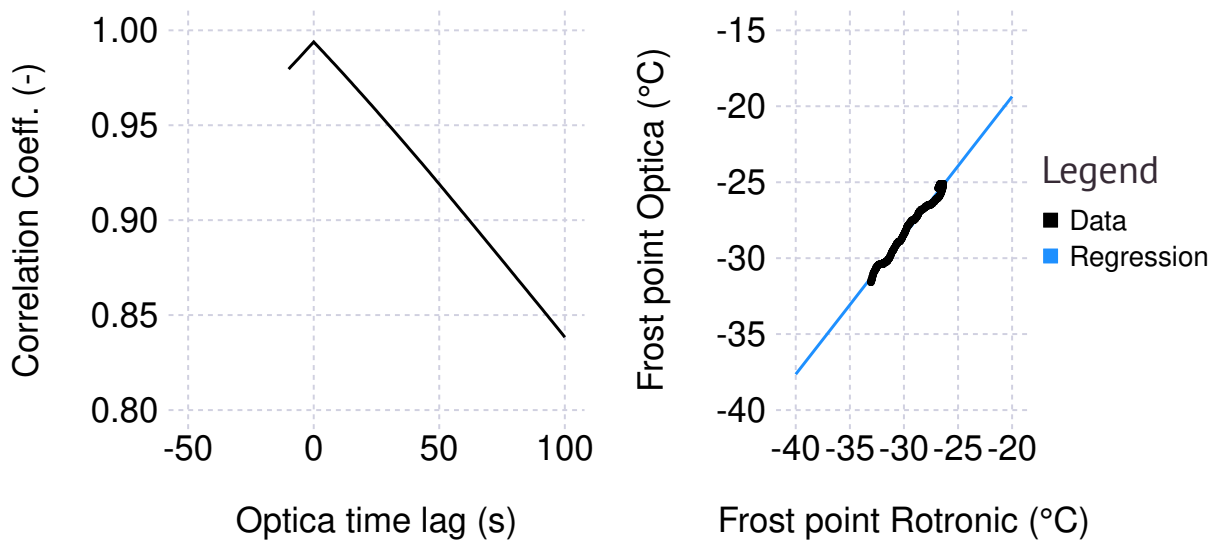

Figure S4. Time evolution of the three measurements (top), the lagged correlation coefficient (bottom left), and the regression line (bottom right). Rot. denotes Rotronic.

The Rotronic sensor has faster response time but lower accuracy than the frost-point sensor. Lag-correlated linear regression is used calibrate the Rotronic sensor against the frost point sensor. Figure S4 shows the time evolution of the measurement and the frost point temperature obtained from the calibrated Rotronic sensor. The calibrated Rotronic frost point temperature is used together with the average of $\mathrm{T} 1$ and $\mathrm{T} 2$ to compute the $\mathrm{RH}$ inside the coalescence chamber. The time-lag derived between the Optica and Rotronic was $0 \mathrm{~s}$. This shows that there is not processing lag in the dew-point sensor, but the data still show oscillations of the dewpoint sensor which is attributed to the heating/cooling cycle of the chilled mirror.

Figure S5 shows the SMPS mode diameter of the coagulated particles as a function of temperature and RH obtained during the $30 \mathrm{~min}$ ramp. The mode diameter is determined by fitting a lognormal size distribution function to the measured distribution. During the ramp temperature decreases and relative humidity increases. If the partial or complete coalescence occurs, the mode diameter decreases. Upon complete coalescence, the mode diameter remains constant. The change in the mode diameter is 

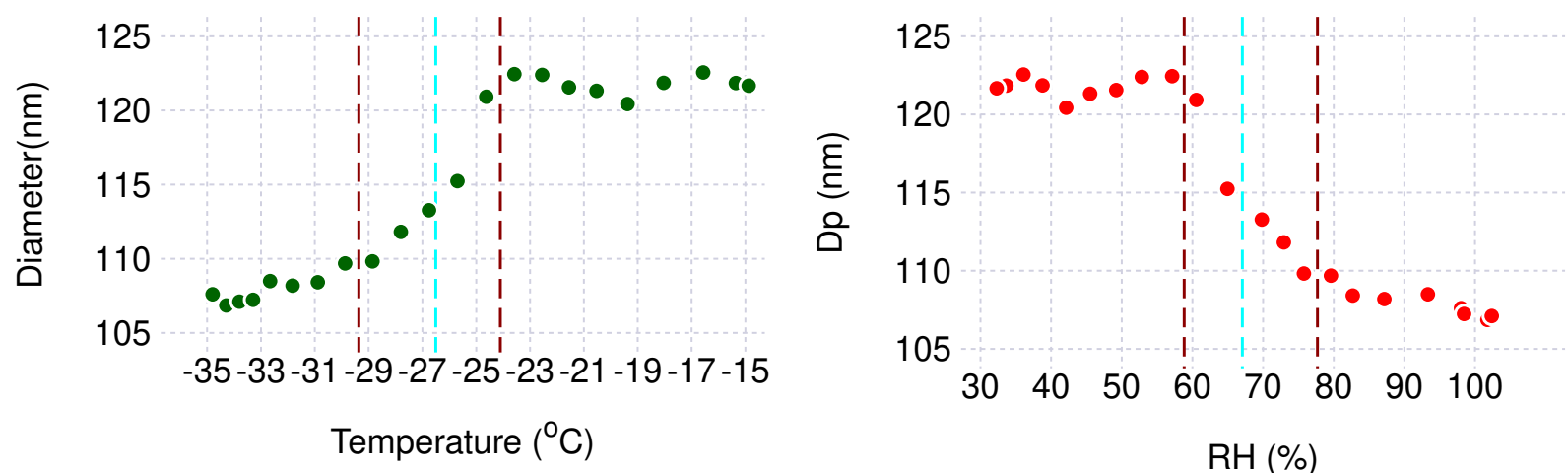

$\mathrm{RH}(\%)$

Figure S5. Evolution of the measured SMPS mode diameter versus temperature (left) and RH (right) for the $30 \mathrm{~min}$ ramp.

typically a few nm (Rothfuss et al., 2019). The diameter data are converted to shape factor data as described in Rothfuss and Petters (2016).

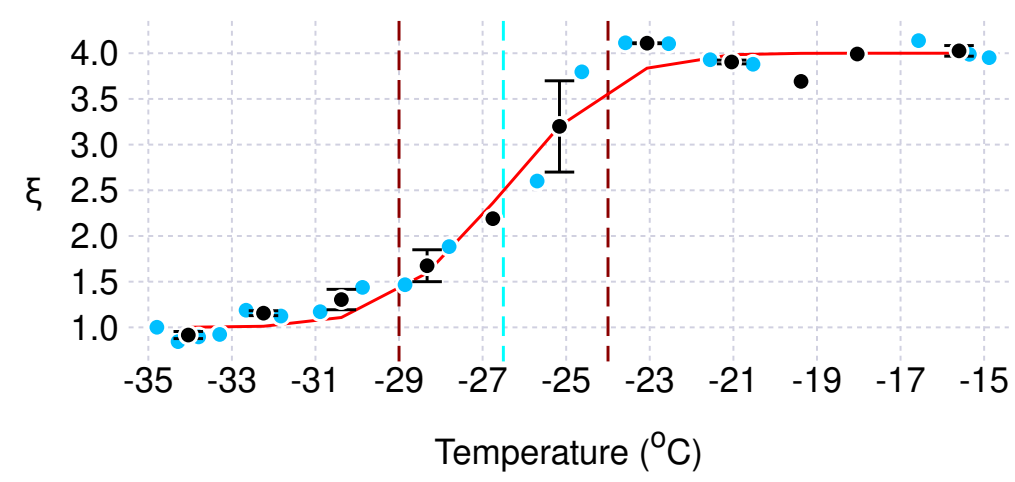

Figure S6. Particle shape parameter $\xi$ versus temperature. Blue circles correspond to mode diameters from the SMPS scans as in Figure S4. Black points correspond to bins of $1.84 \pm 0.32^{\circ} \mathrm{C}$. The red line corresponds to the logistic fit defined in Eq. (1)).

Figure S6 shows the resulting relationship between particle shape parameter $\xi$ versus temperature. The midpoint of the $\xi$ vs temperature curve where $\xi=2.5$ (vertical cyan dotted line). The corresponding midpoint temperature is $T_{0}=-26.5^{\circ} \mathrm{C}$ and $\sigma=2.15$. The calculated viscosity through the modified Frenkel sintering (Pokluda et al., 1997) is $4.79 \times 10^{7} \mathrm{~Pa}$ s where the theory uses the $\xi$, residence time $(60 \mathrm{~s})$, monomer diameter of the particles $(90 \mathrm{~nm})$, and the surface tension of sucrose $\left(0.08 \mathrm{Jm}^{-2}\right)$, (Table 1 , main manuscript). The corresponding $\mathrm{RH}$ value $(R H=67.4 \%)$ is averaged between the temperatures $-27.5^{\circ} \mathrm{C}$ and $-25.5^{\circ} \mathrm{C}$ for the range of RHOptica. The vertical dark red dotted lines show the temperatures where $\xi=1.5$ and $\xi=3.5$. The corresponding RH, T and viscosity values can be found in Table 1 (main manuscript). In Figure S4, the RH and temperature values are corresponding to the conditions where $\xi=1.5$. 


\subsection{Citric Acid Experiments}

\subsubsection{1_20190508CA15:}

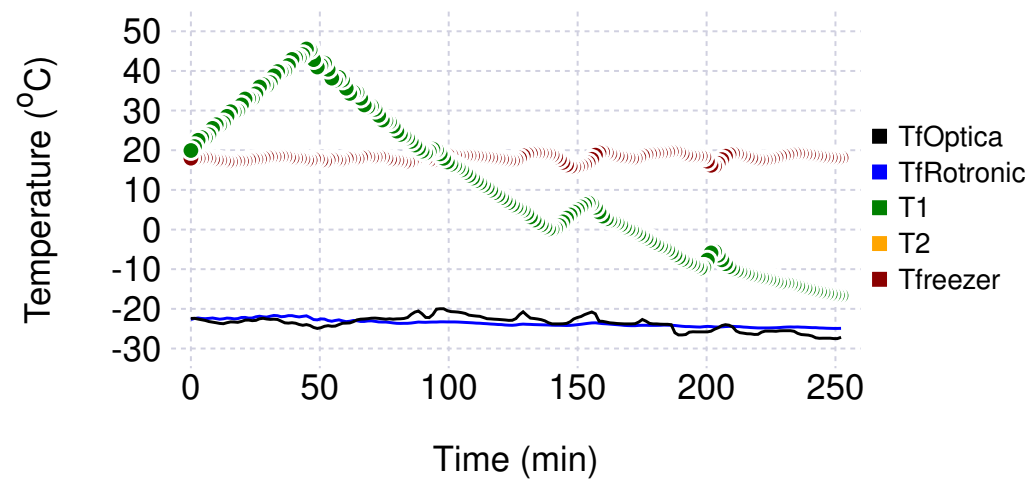

Figure S7. Variation of absolute temperatures and frost point temperatures over the duration of the experiment.
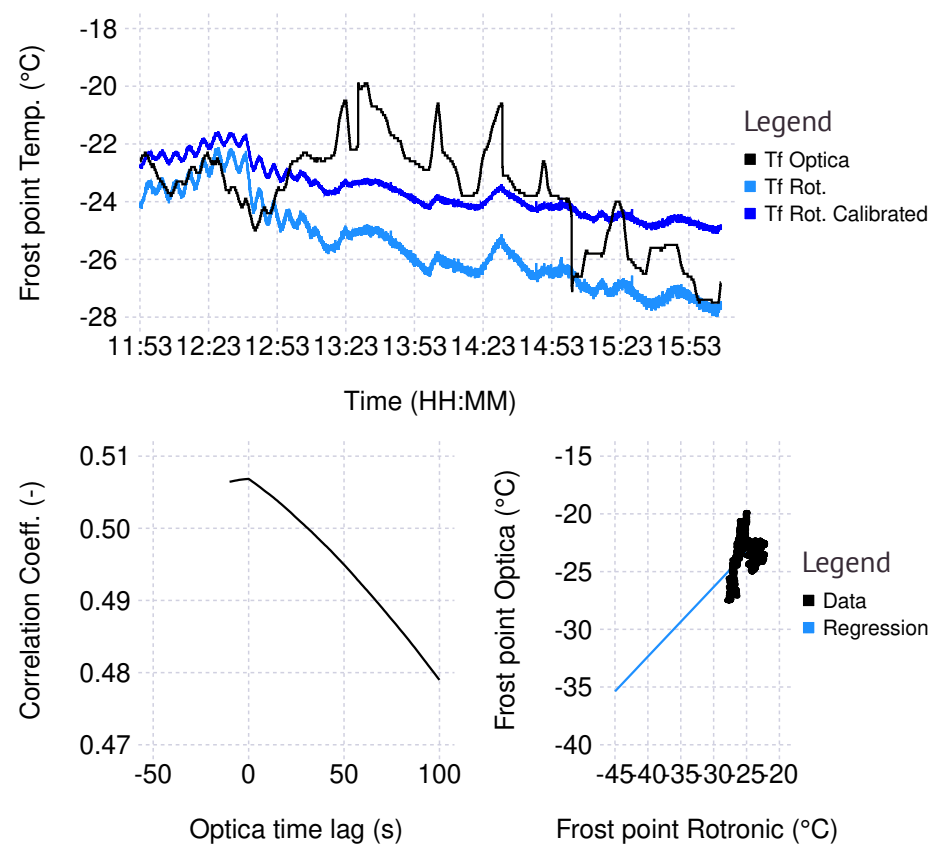

Figure S8. Calibration of RH sensors. 

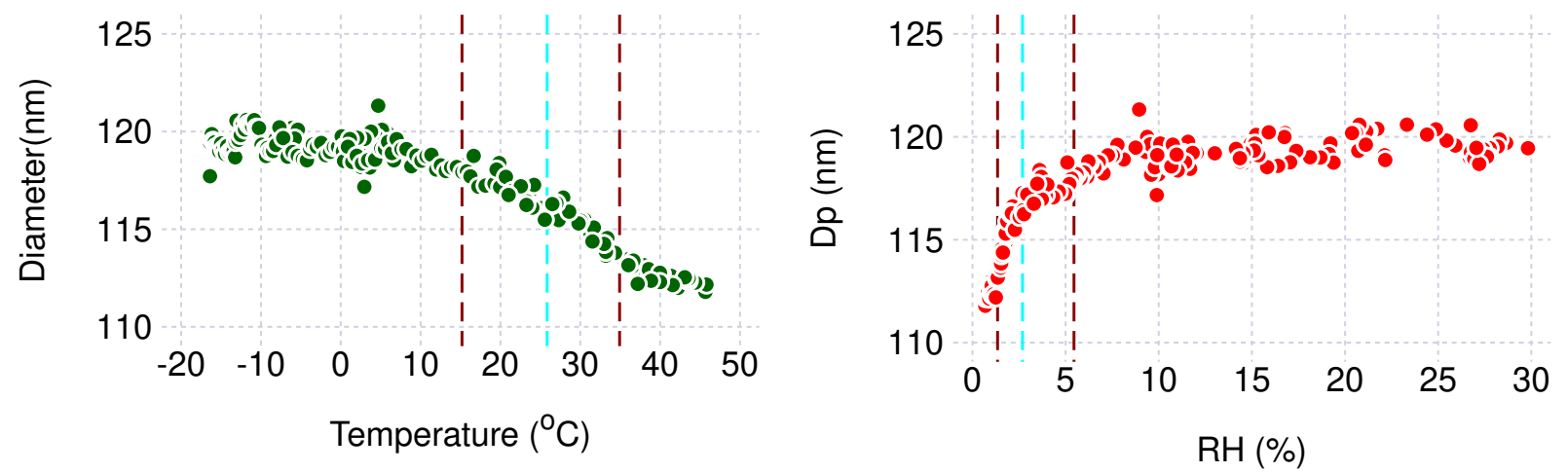

Figure S9. Evolution of the measured SMPS mode diameter versus temperature (left) and RH (right) for the ramp.

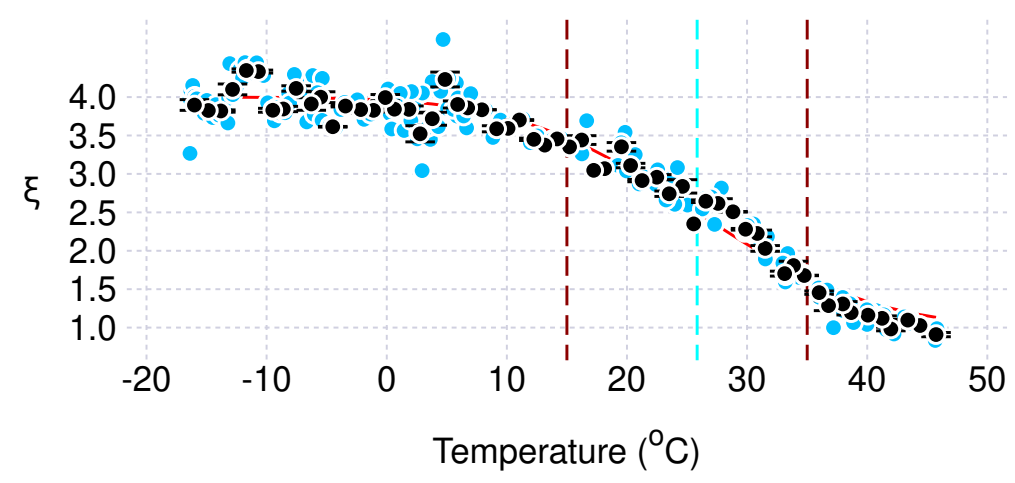

Figure S10. Particle shape parameter $\xi$ versus temperature 
4.1.2 2_20190509CA16:

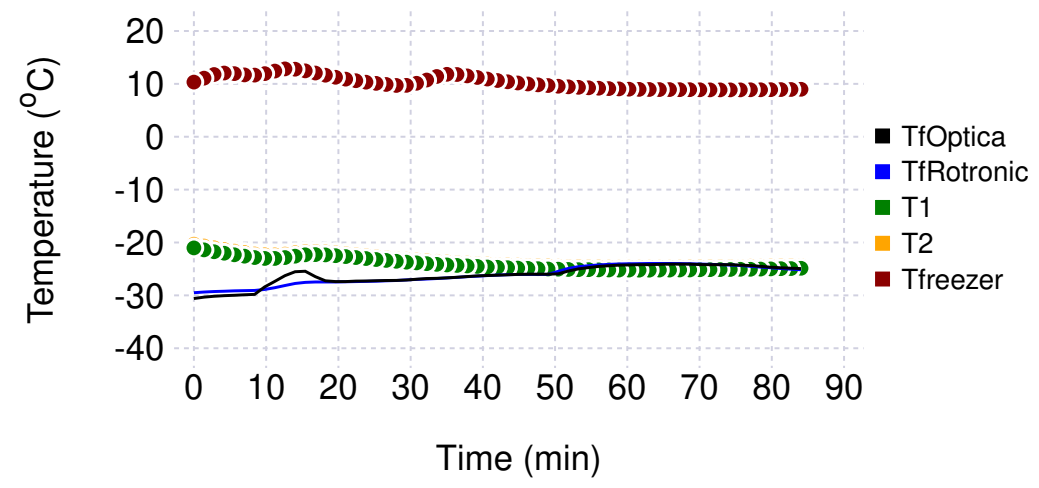

Figure S11. Variation of absolute temperatures and frost point temperatures over the duration of the experiment.
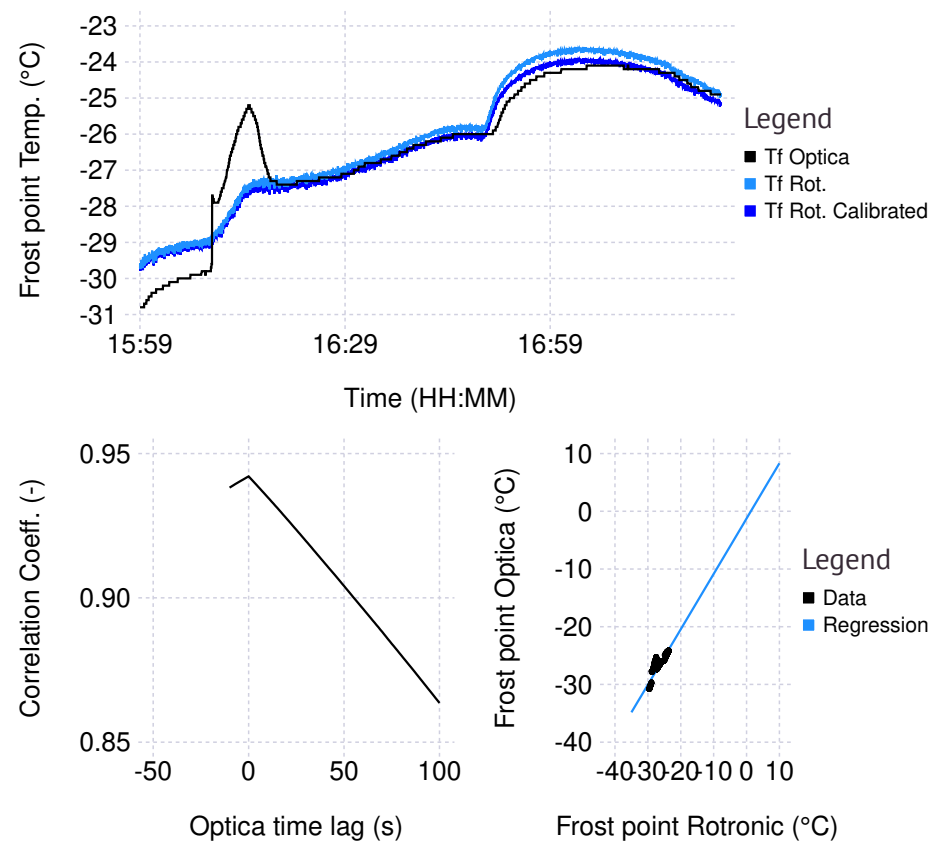

Figure S12. Calibration of RH sensors. 

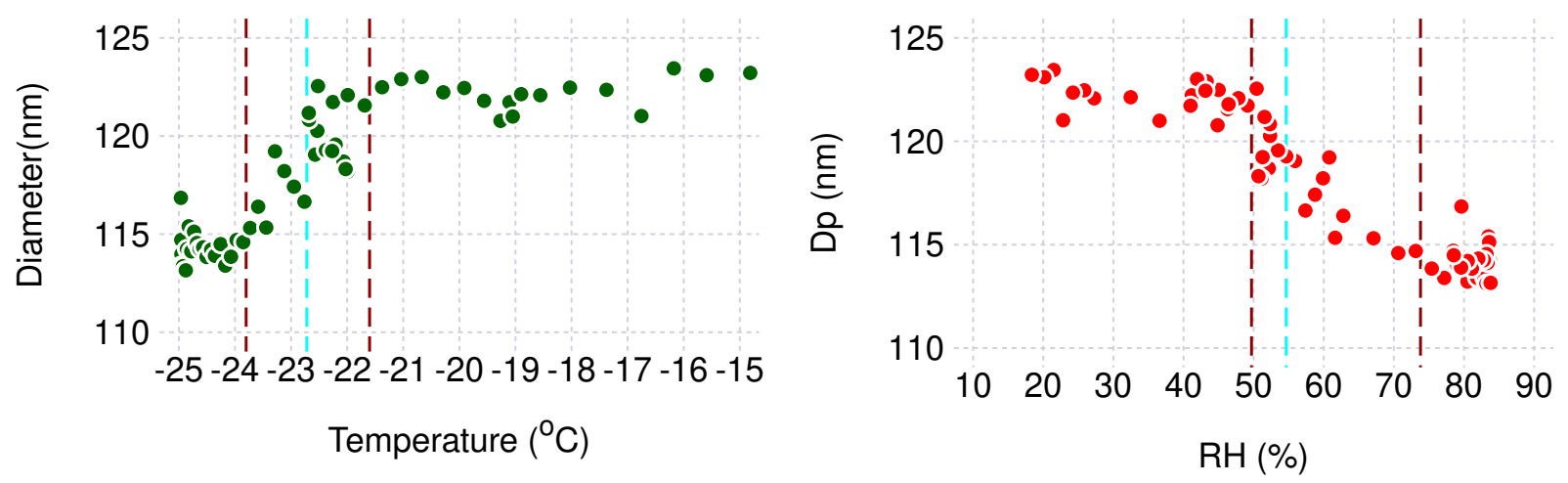

Figure S13. Evolution of the measured SMPS mode diameter versus temperature (left) and RH (right) for the min ramp.

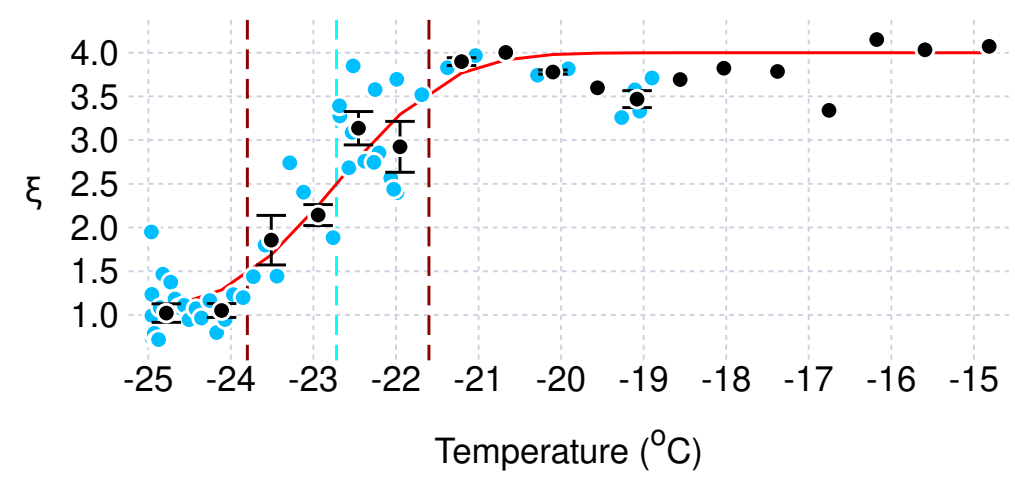

Figure S14. Particle shape parameter $\xi$ versus temperature 
4.1.3 3_20190520CA19:

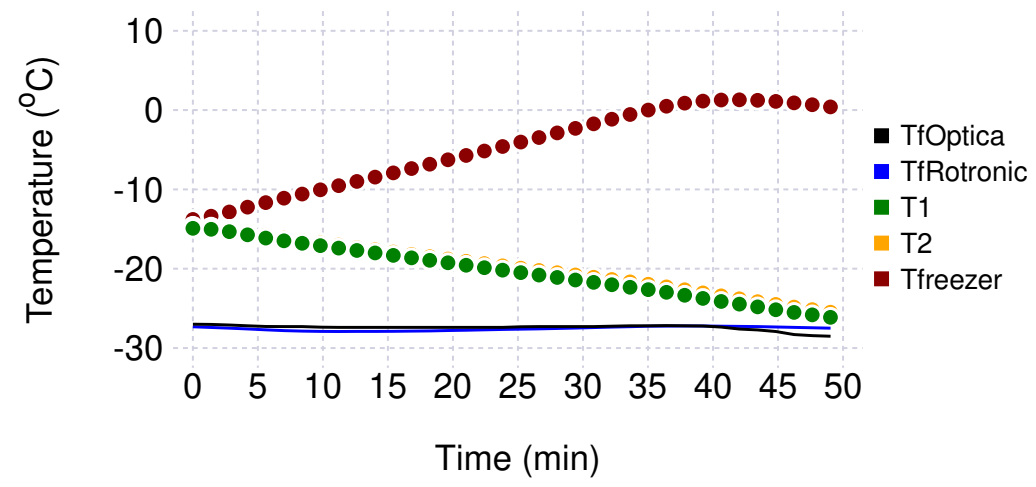

Figure S15. Variation of absolute temperatures and frost point temperatures over the duration of the experiment.

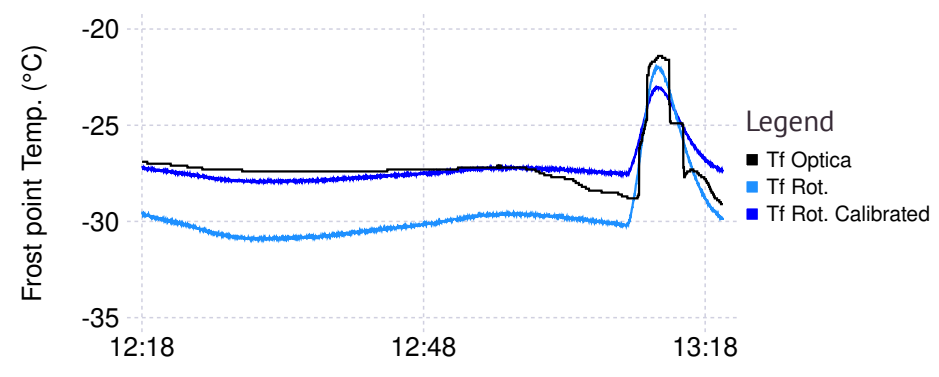

Time (HH:MM)

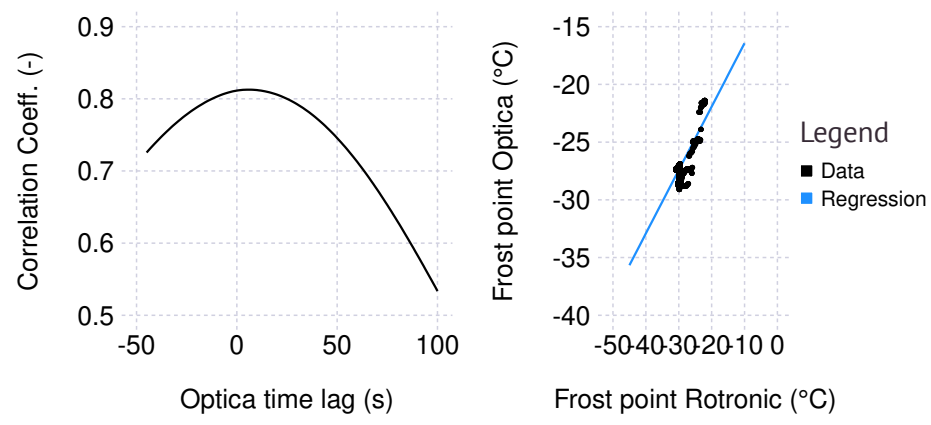

Figure S16. Calibration of RH sensors. 

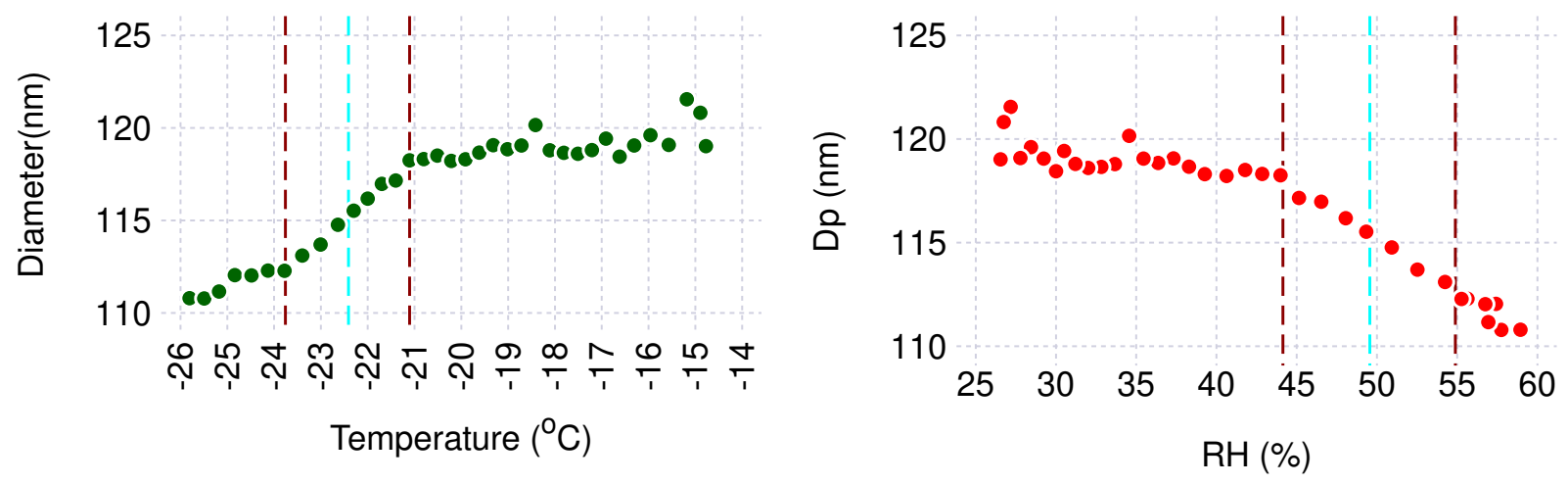

Figure S17. Evolution of the measured SMPS mode diameter versus temperature (left) and RH (right) for the ramp.

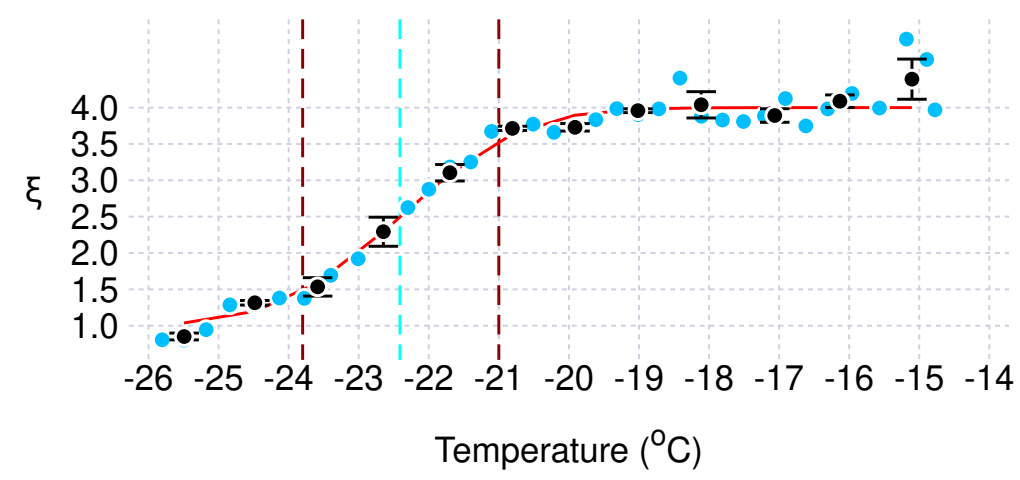

Figure S18. Particle shape parameter $\xi$ versus temperature 


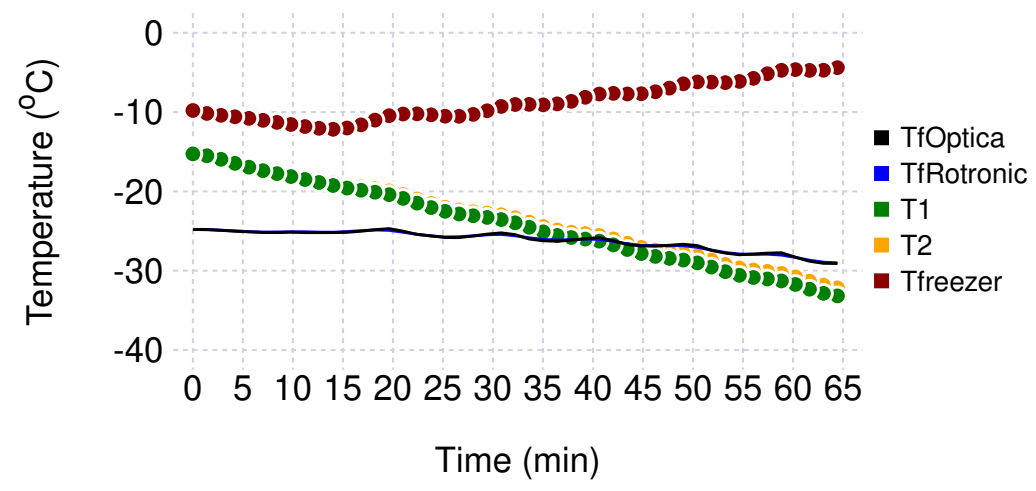

Figure S19. Variation of absolute temperatures and frost point temperatures over the duration of the experiment.
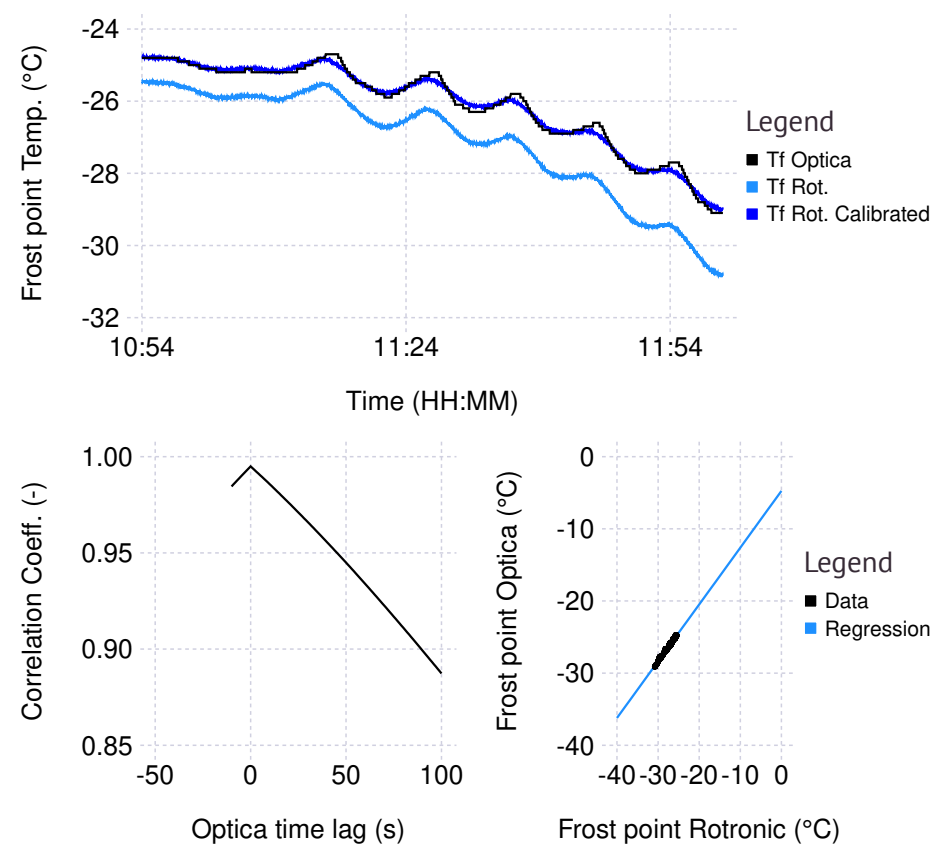

Figure S20. Calibration of RH sensors. 

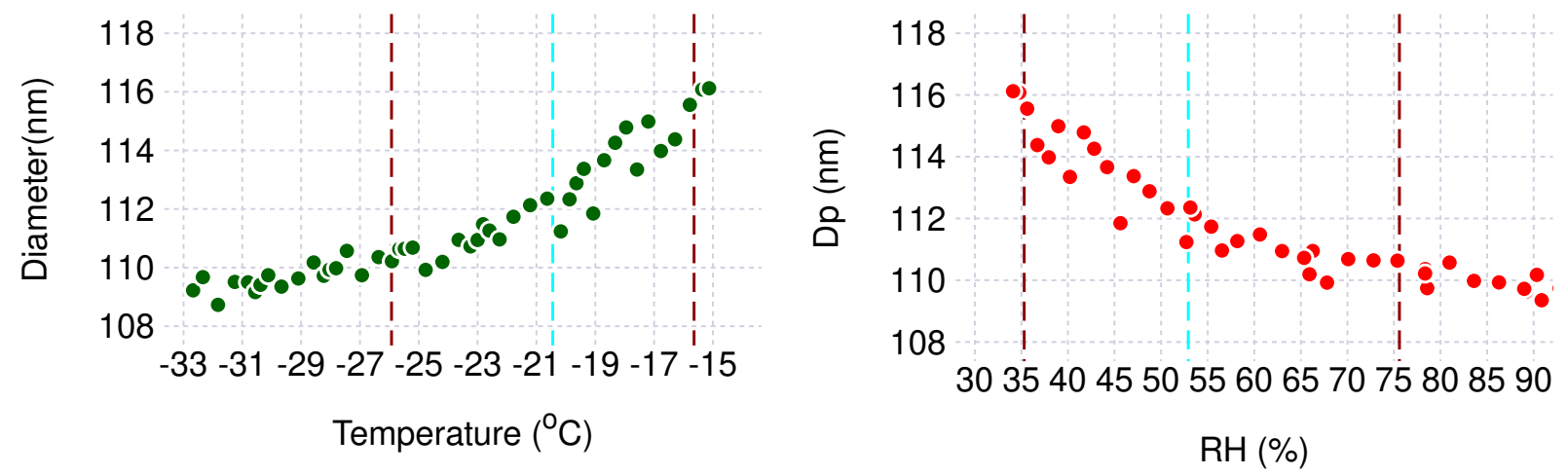

Figure S21. Evolution of the measured SMPS mode diameter versus temperature (left) and RH (right) for the ramp.

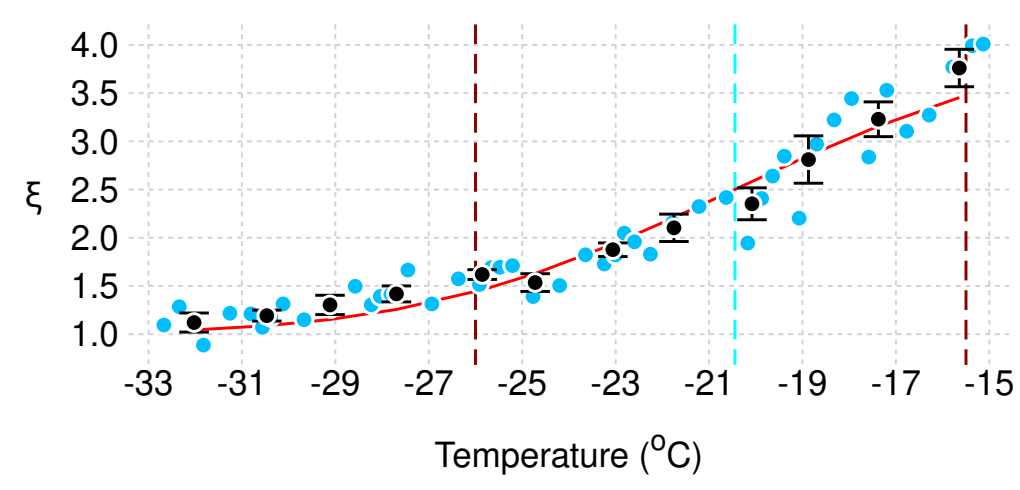

Figure S22. Particle shape parameter $\xi$ versus temperature 
4.1.5 5_20190528CA23:

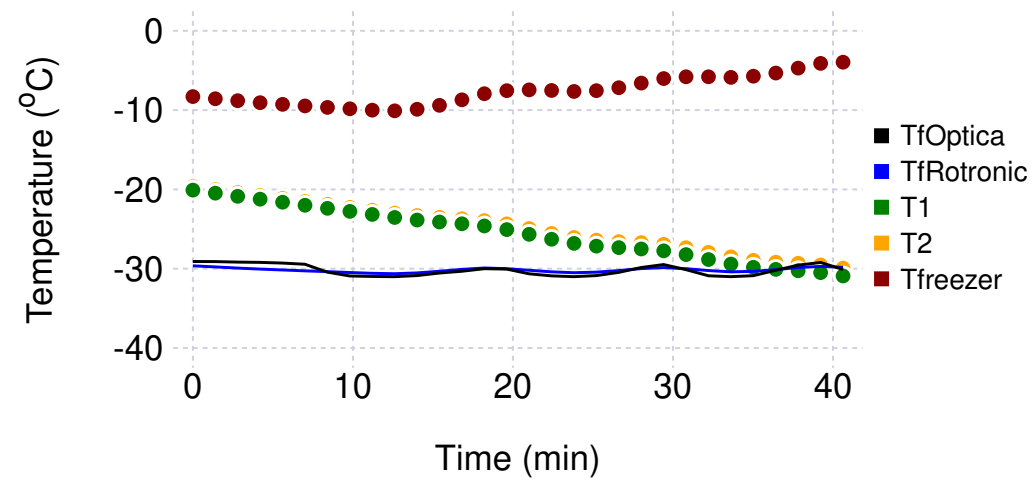

Figure S23. Variation of absolute temperatures and frost point temperatures over the duration of the experiment.
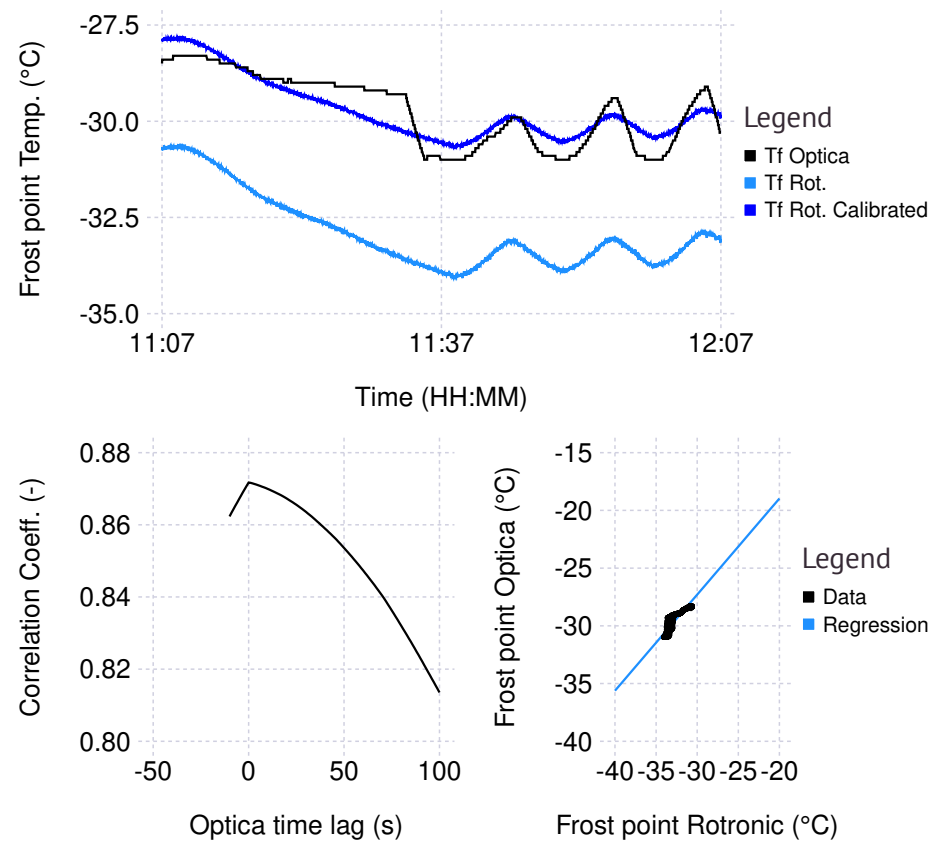

Figure S24. Calibration of RH sensors. 

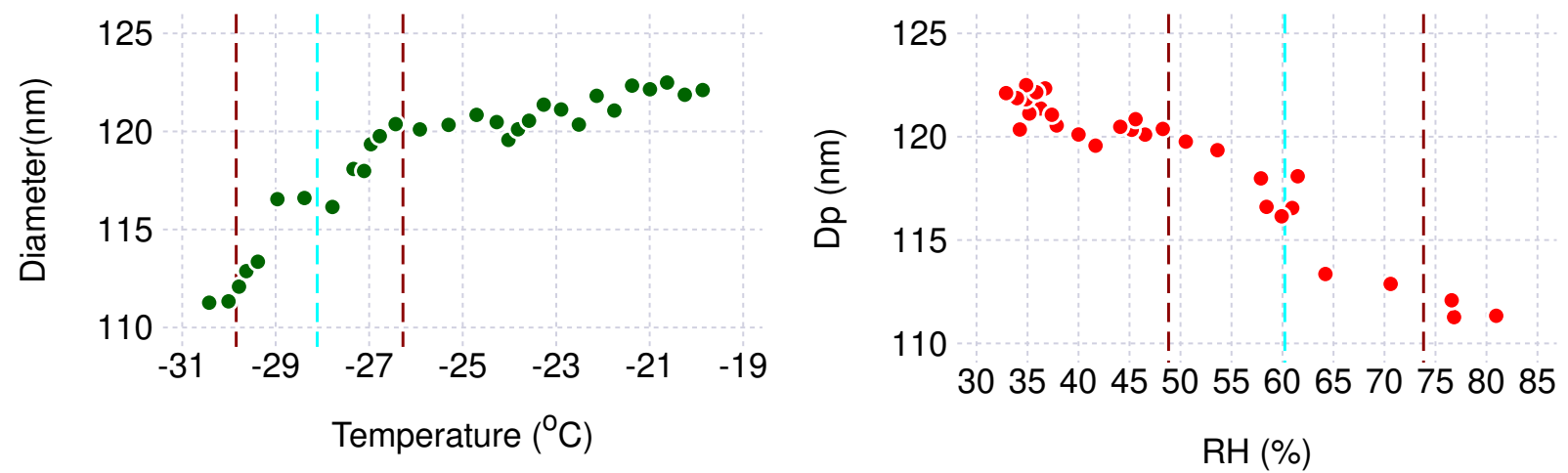

Figure S25. Evolution of the measured SMPS mode diameter versus temperature (left) and RH (right) for the ramp.

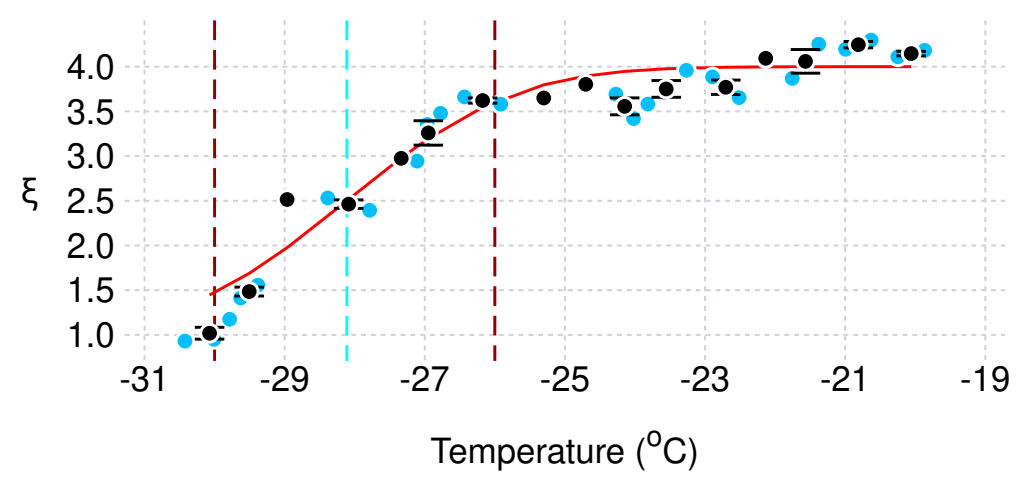

Figure S26. Particle shape parameter $\xi$ versus temperature 


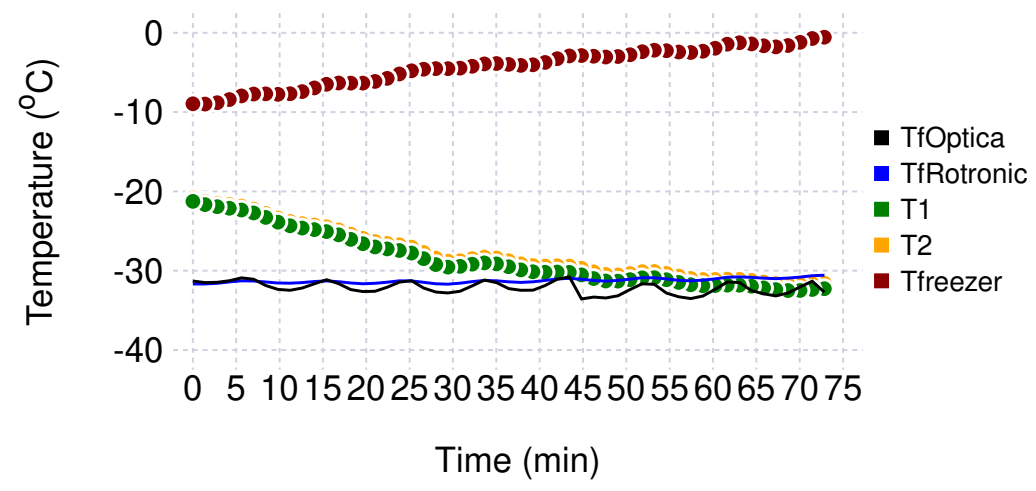

Figure S27. Variation of absolute temperatures and frost point temperatures over the duration of the experiment.
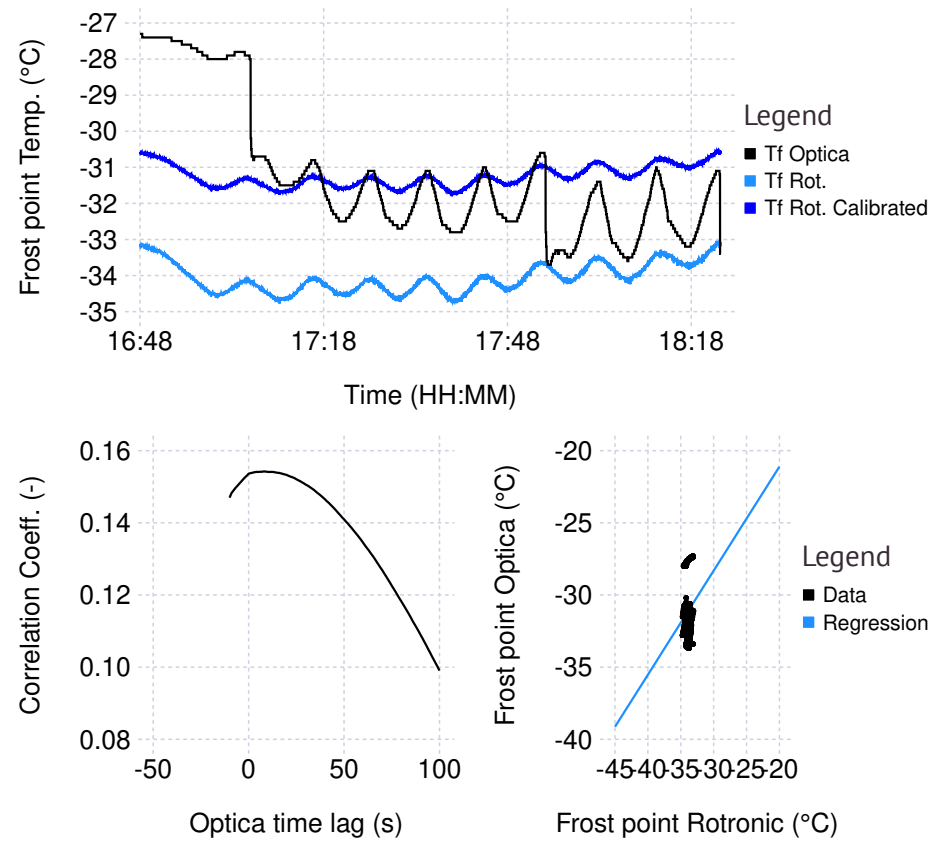

Figure S28. Calibration of RH sensors. 

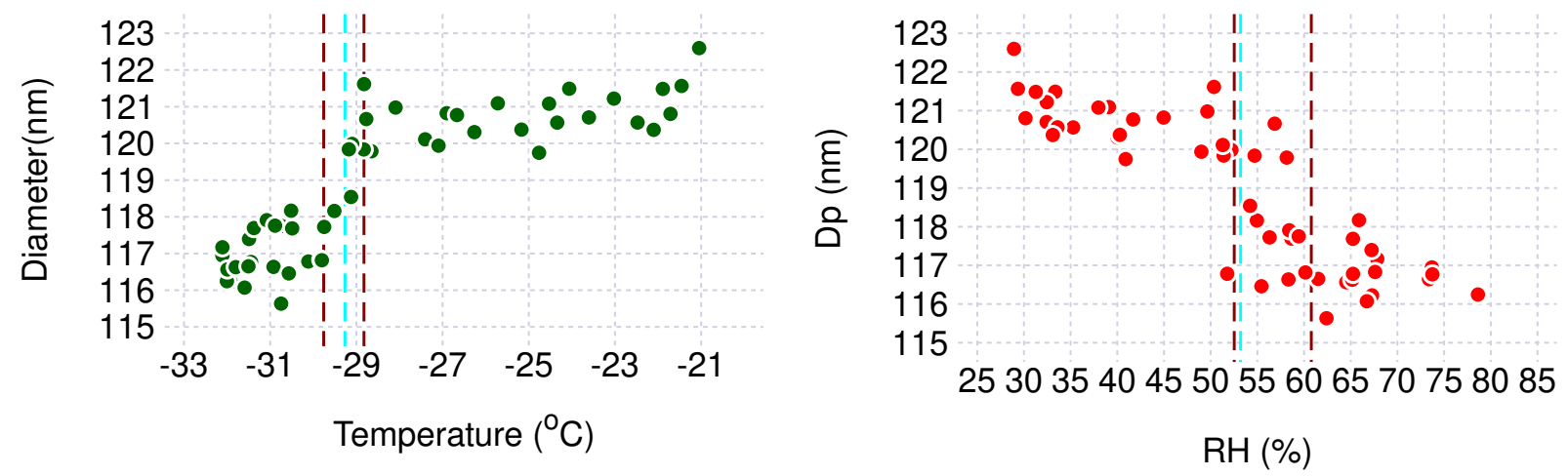

Figure S29. Evolution of the measured SMPS mode diameter versus temperature (left) and RH (right) for the ramp.

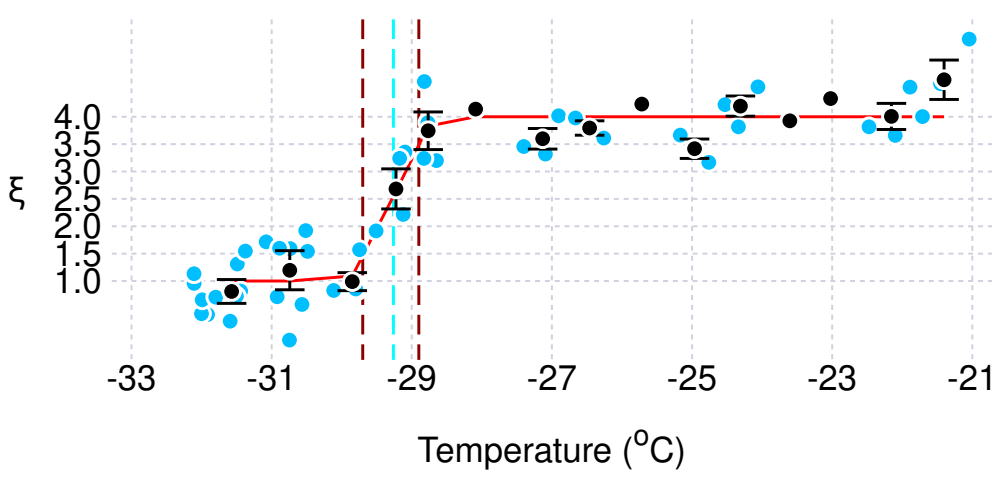

Figure S30. Particle shape parameter $\xi$ versus temperature 


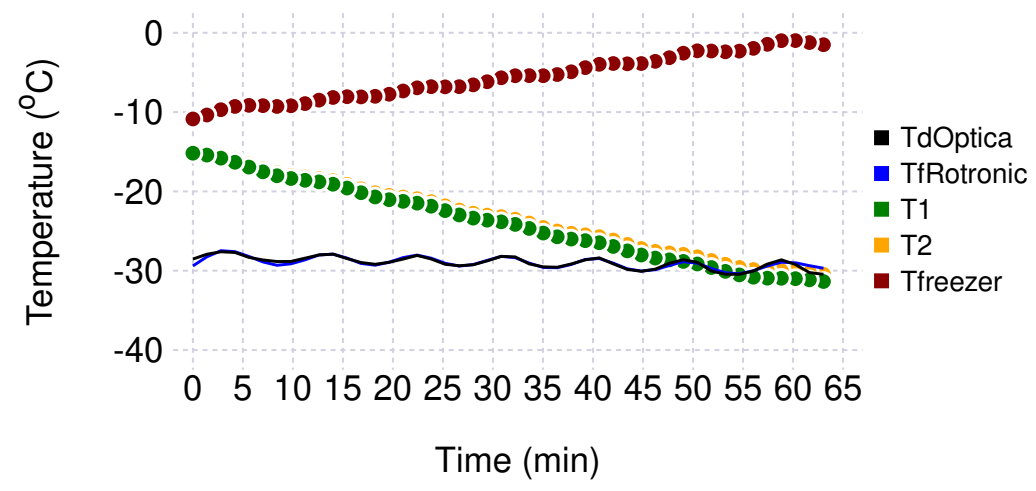

Figure S31. Variation of absolute temperatures and frost point temperatures over the duration of the experiment.
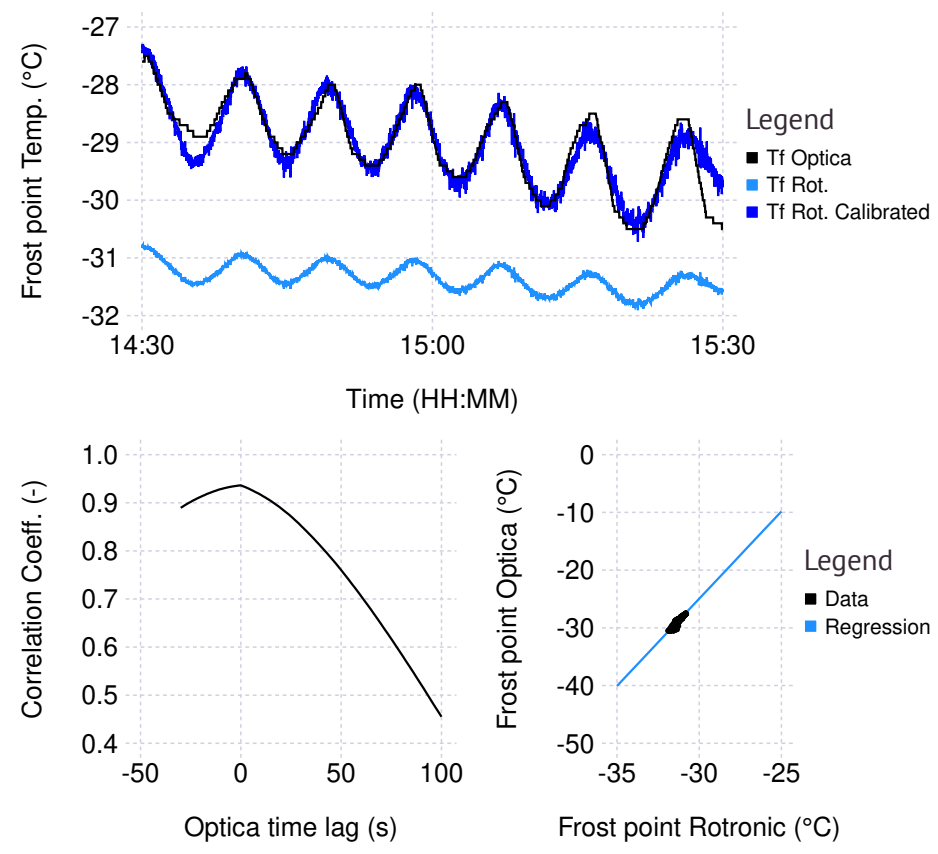

Figure S32. Calibration of RH sensors. 

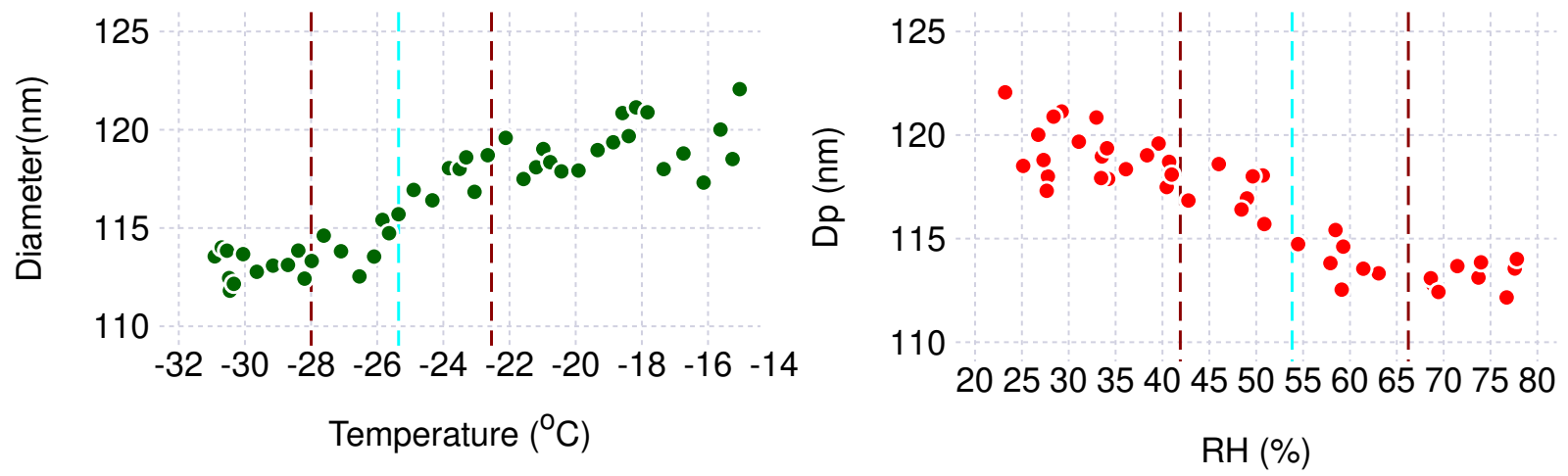

Figure S33. Evolution of the measured SMPS mode diameter versus temperature (left) and RH (right) for the ramp.

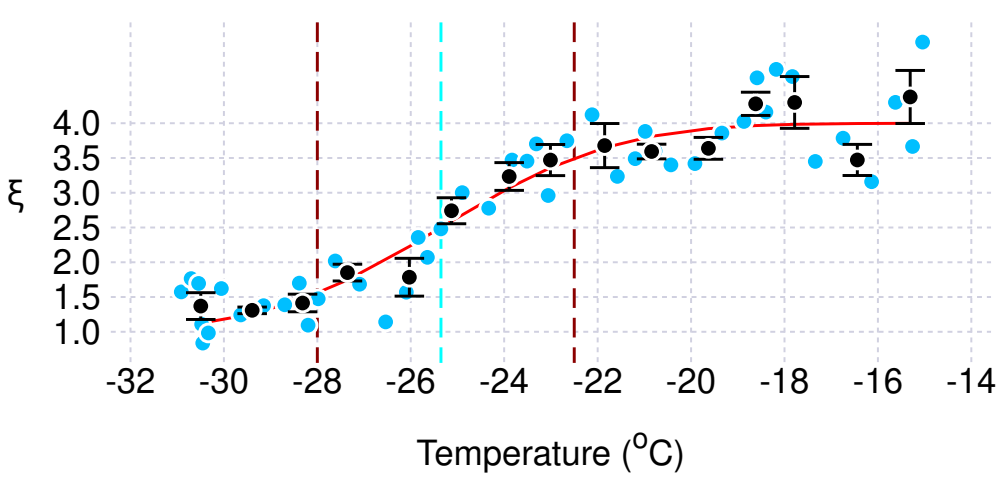

Figure S34. Particle shape parameter $\xi$ versus temperature 
4.1.8 8_20190603CA27:

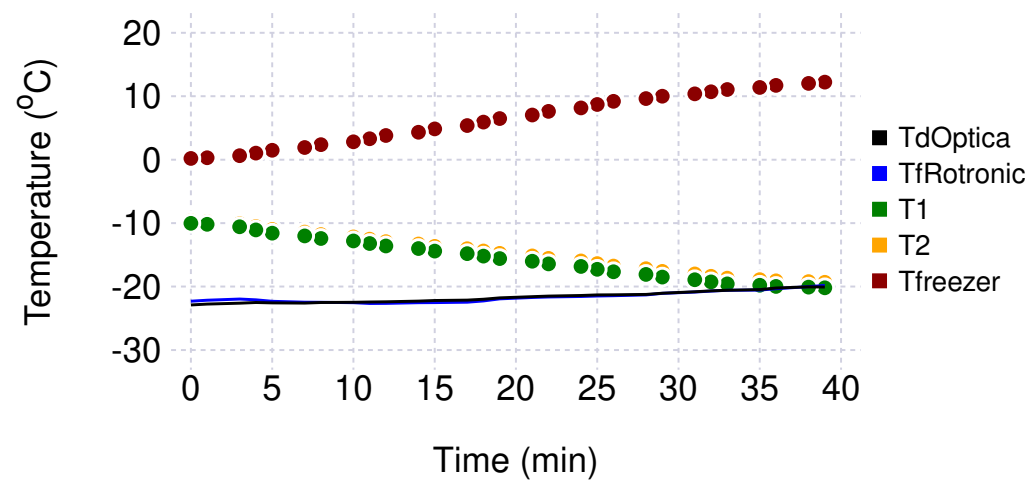

Figure S35. Variation of absolute temperatures and frost point temperatures over the duration of the experiment.
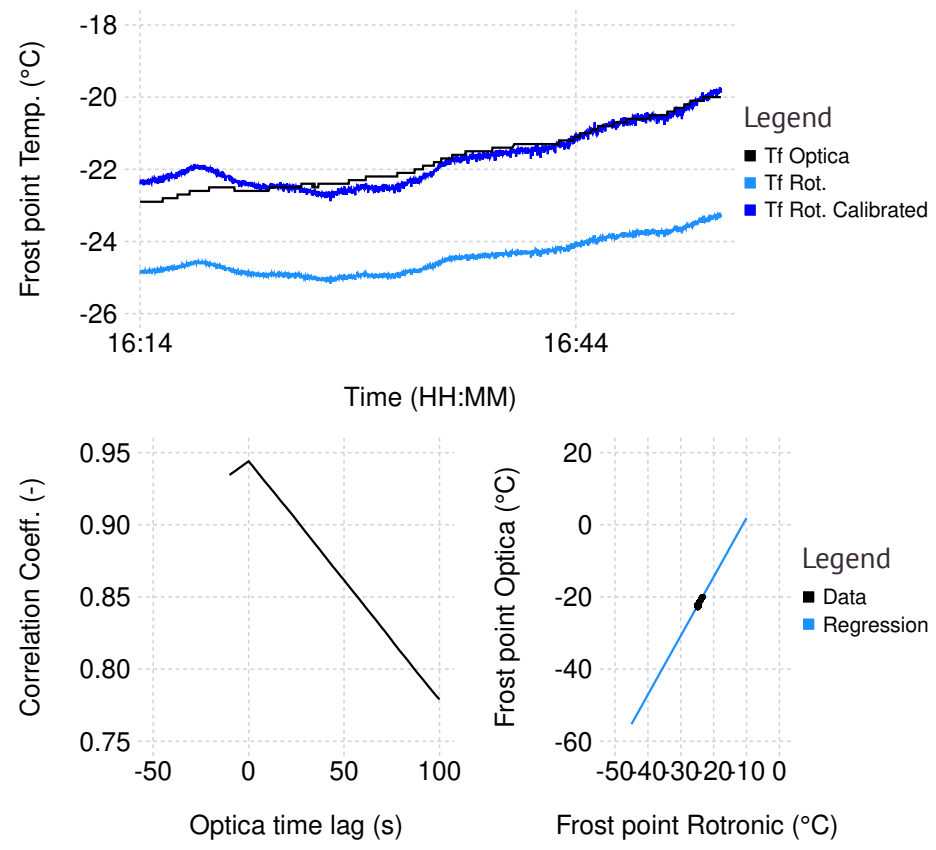

Figure S36. Calibration of RH sensors. 

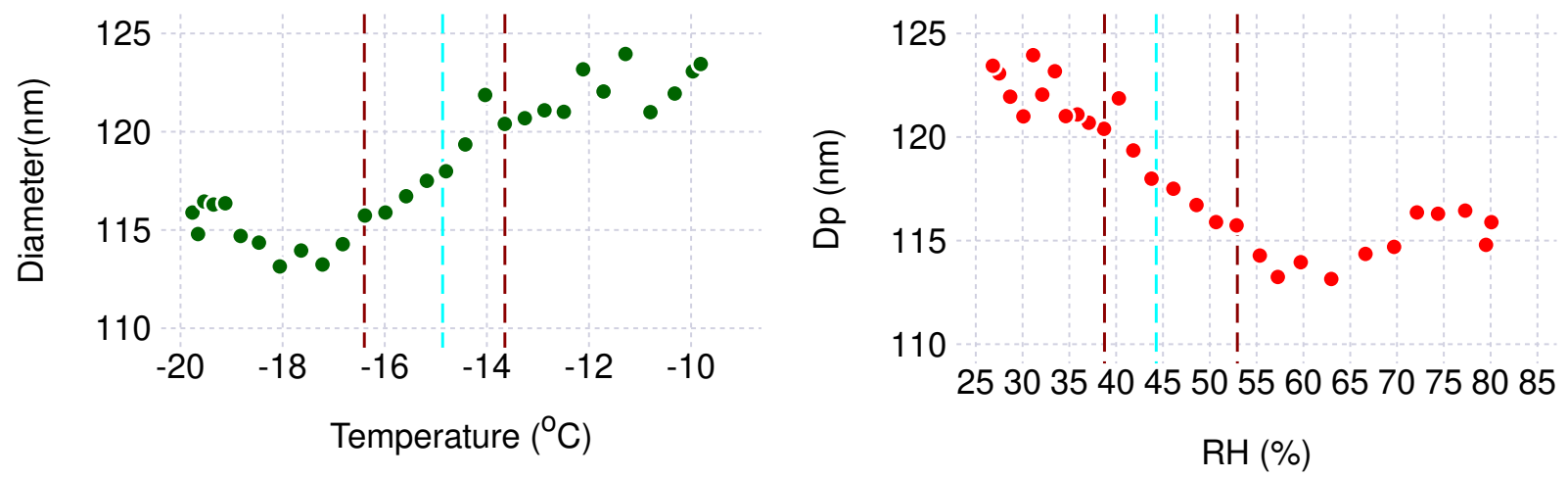

Figure S37. Evolution of the measured SMPS mode diameter versus temperature (left) and RH (right) for the ramp.

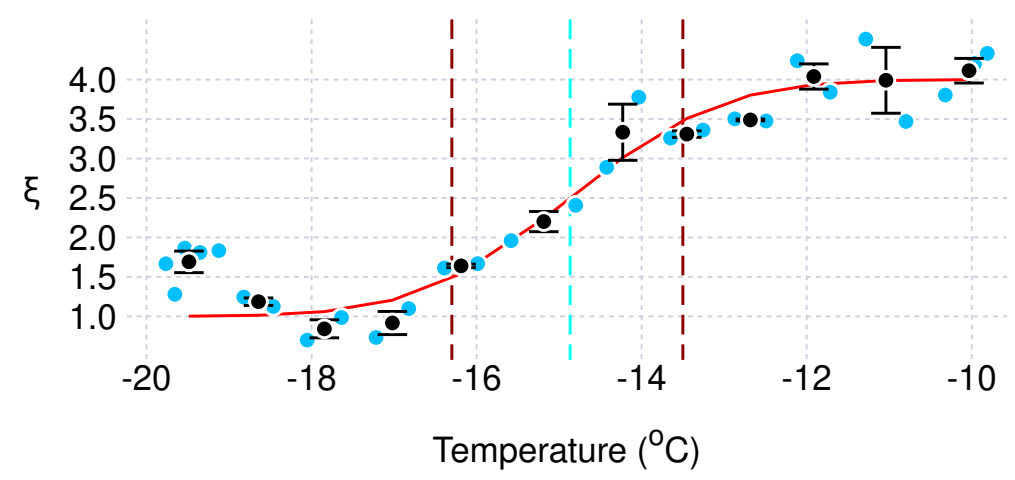

Figure S38. Particle shape parameter $\xi$ versus temperature 


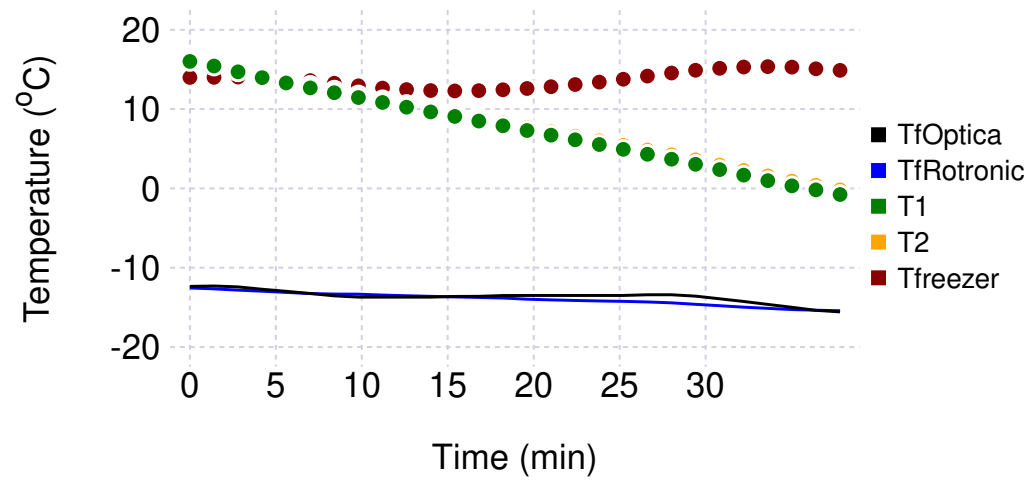

Figure S39. Variation of absolute temperatures and frost point temperatures over the duration of the experiment.
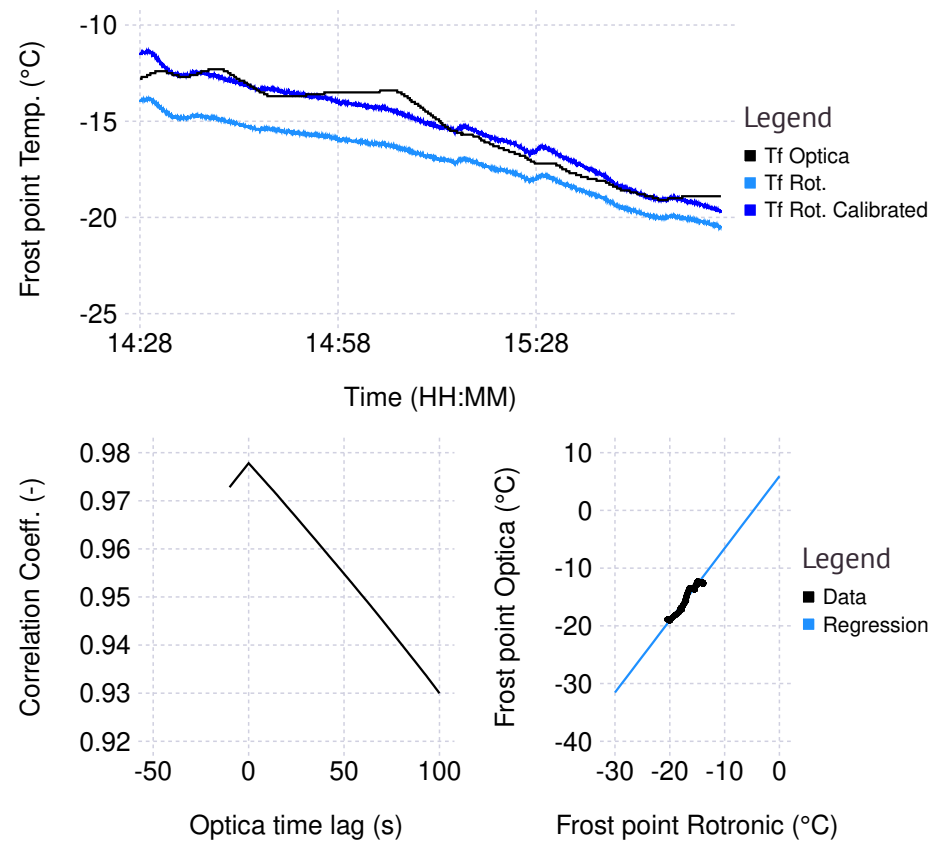

Figure S40. Calibration of RH sensors. 

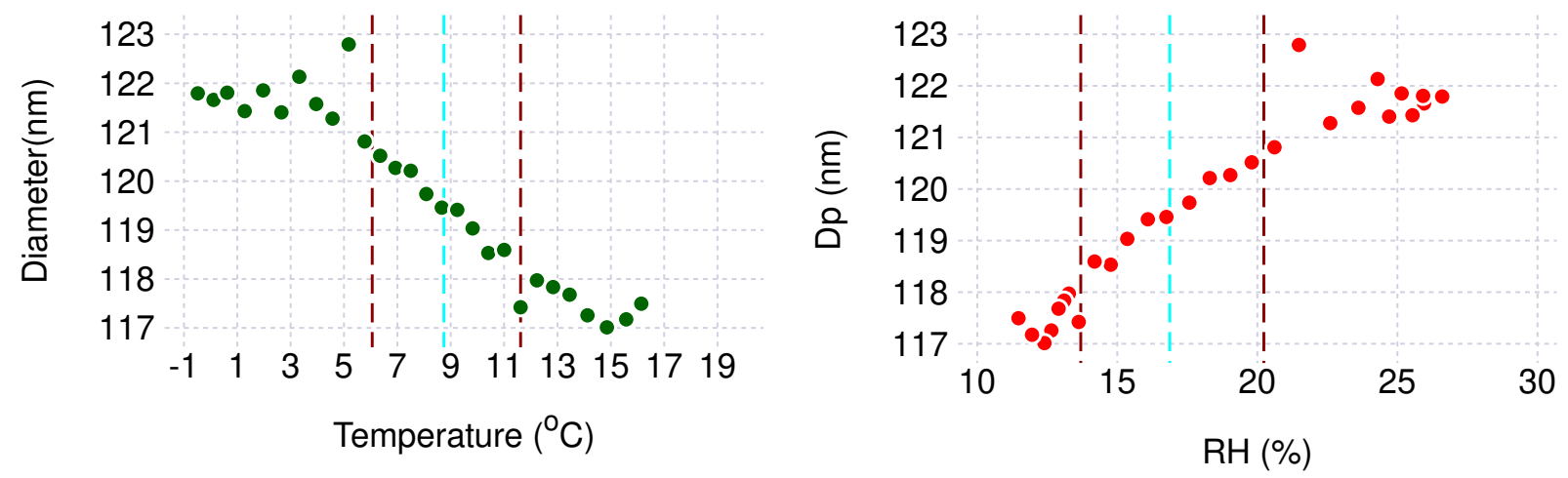

Figure S41. Evolution of the measured SMPS mode diameter versus temperature (left) and RH (right) for the ramp.

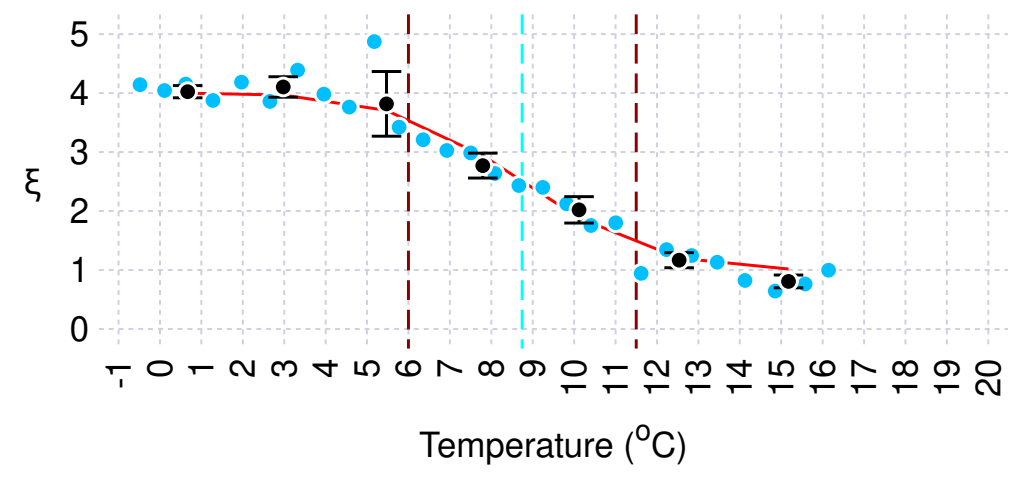

Figure S42. Particle shape parameter $\xi$ versus temperature 


\subsection{Sucrose experiments:}

\subsubsection{0_20190429S10:}

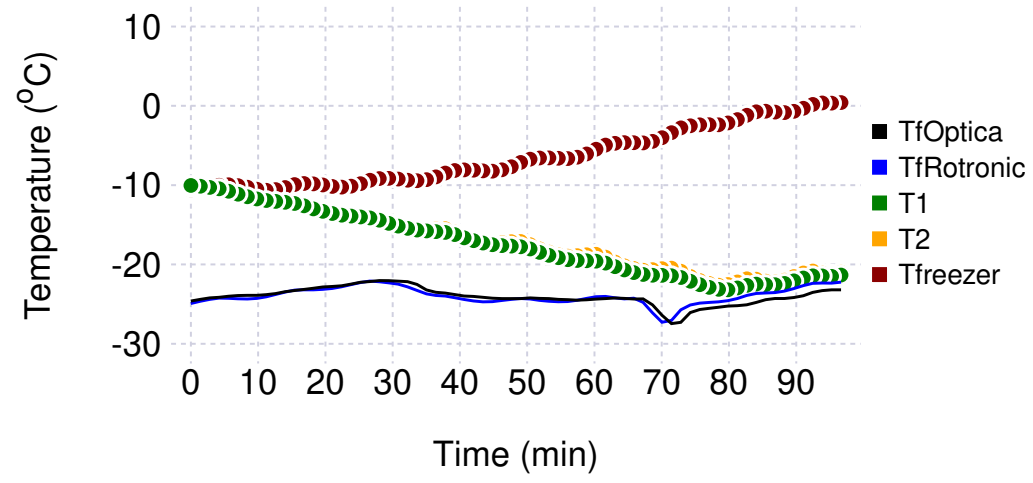

Figure S43. Variation of absolute temperatures and frost point temperatures over the duration of the experiment.
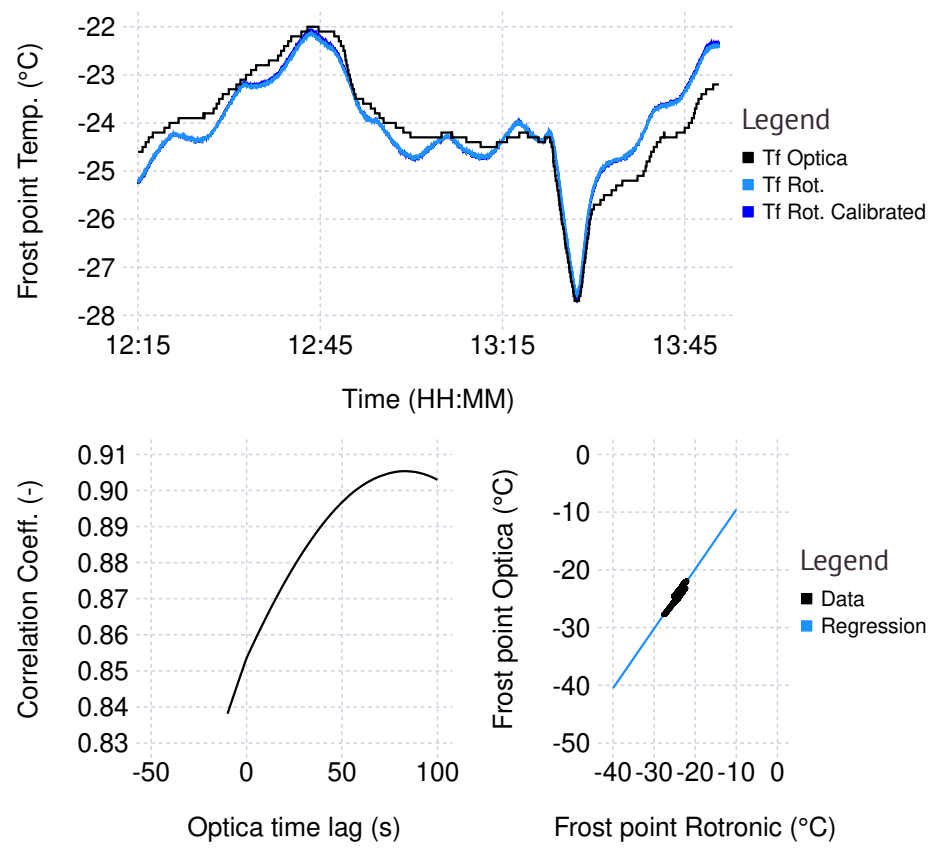

Figure S44. Calibration of RH sensors. 

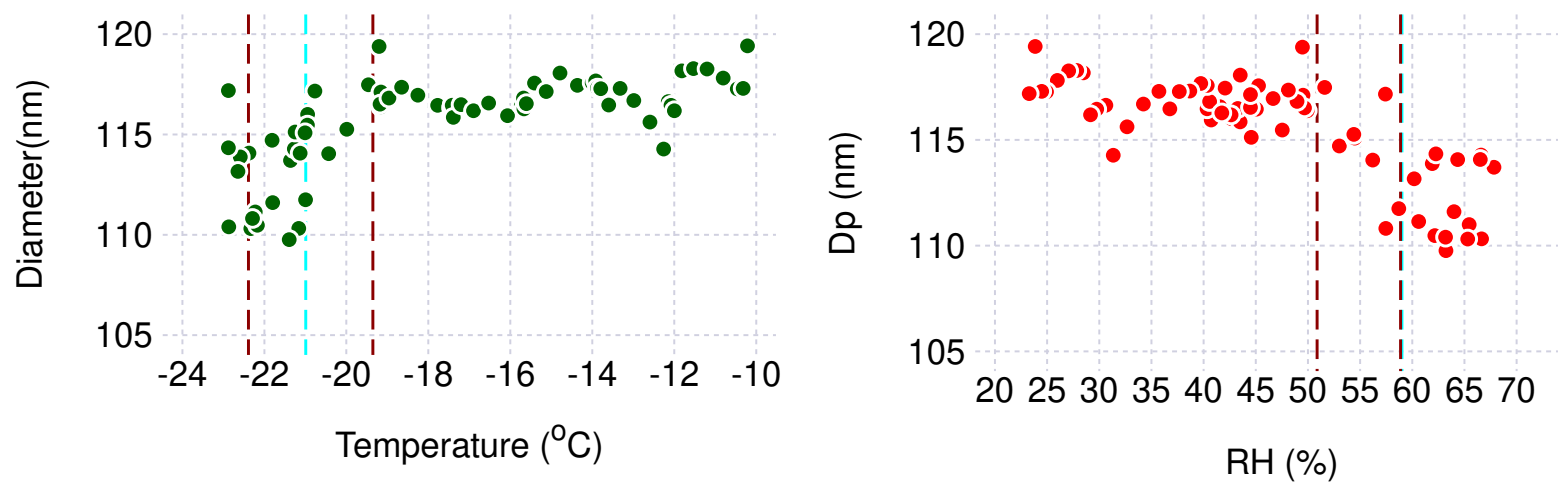

Figure S45. Evolution of the measured SMPS mode diameter versus temperature (left) and RH (right) for the ramp.

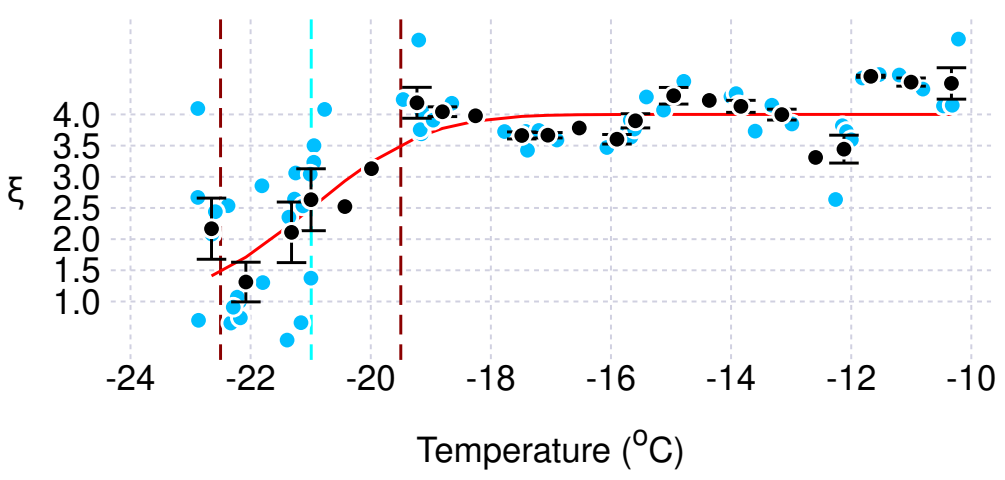

Figure S46. Particle shape parameter $\xi$ versus temperature 


\subsubsection{1_20190521S20:}

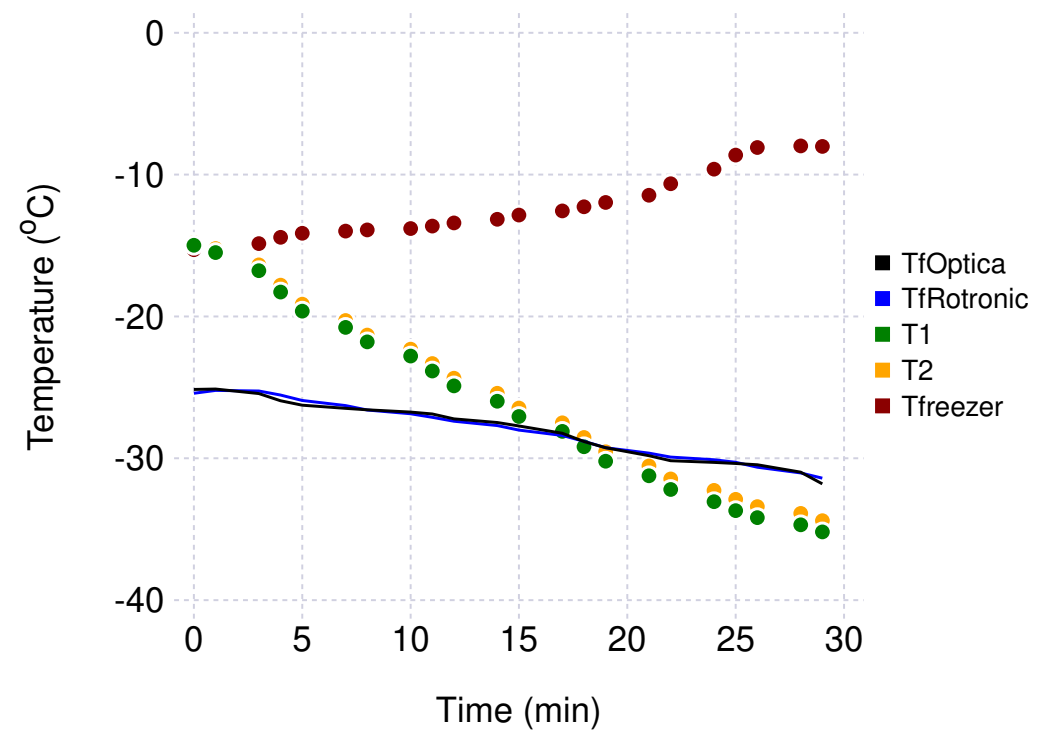

Figure S47. Variation of absolute temperatures and frost point temperatures over the duration of the experiment.

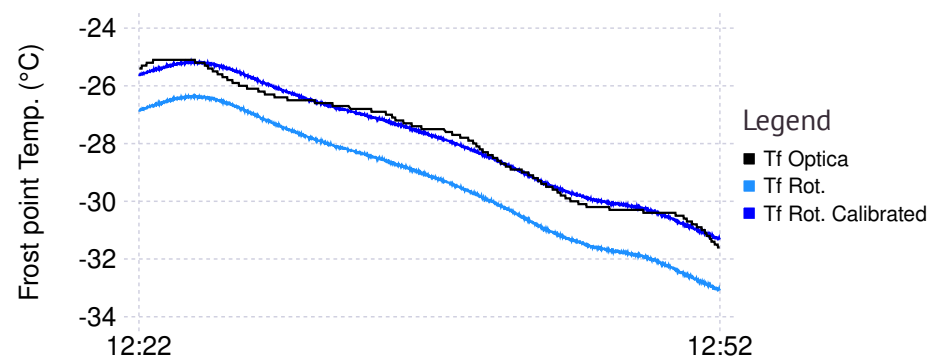

Time (HH:MM)
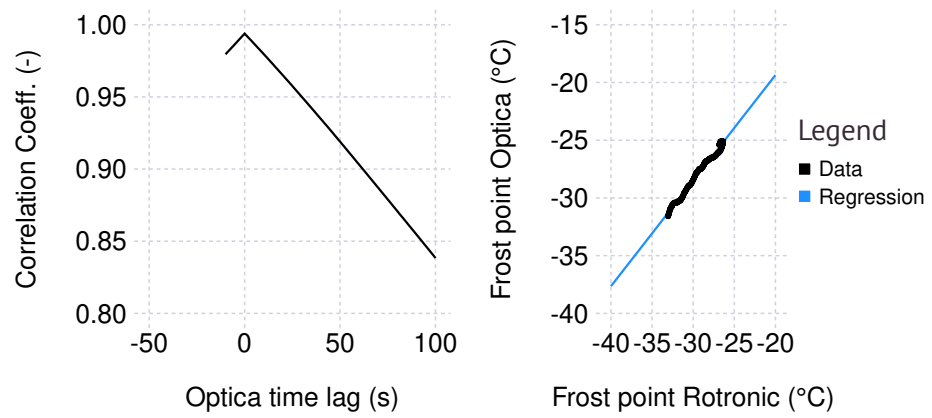

Figure S48. Calibration of RH sensors. 

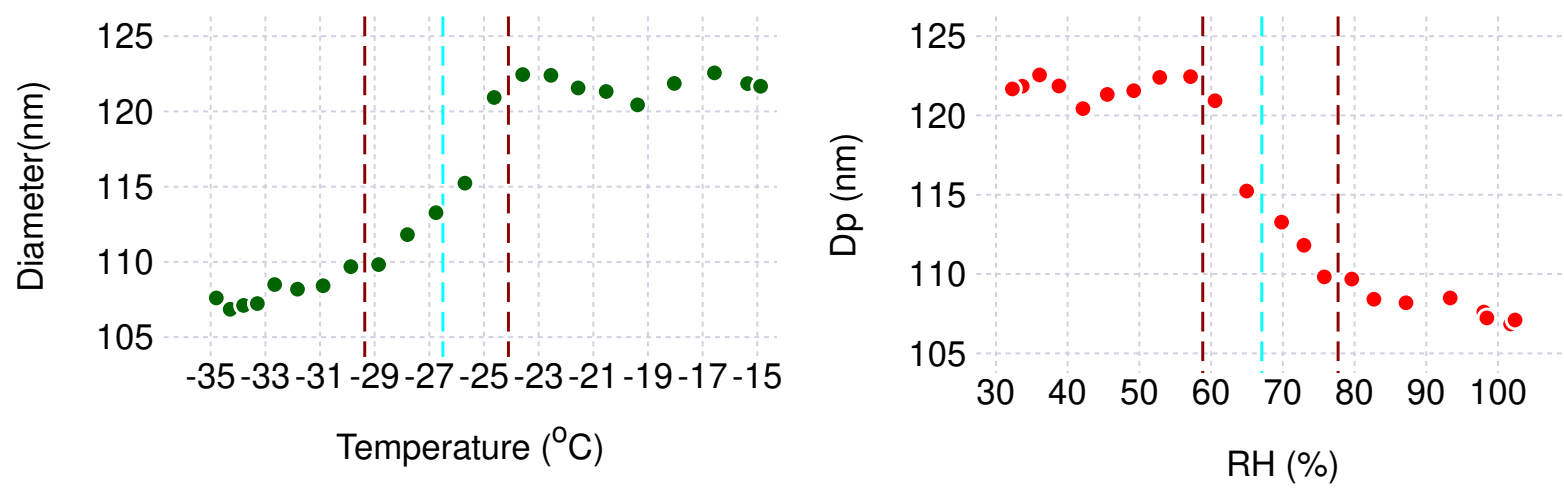

Figure S49. Evolution of the measured SMPS mode diameter versus temperature (left) and RH (right) for the ramp.

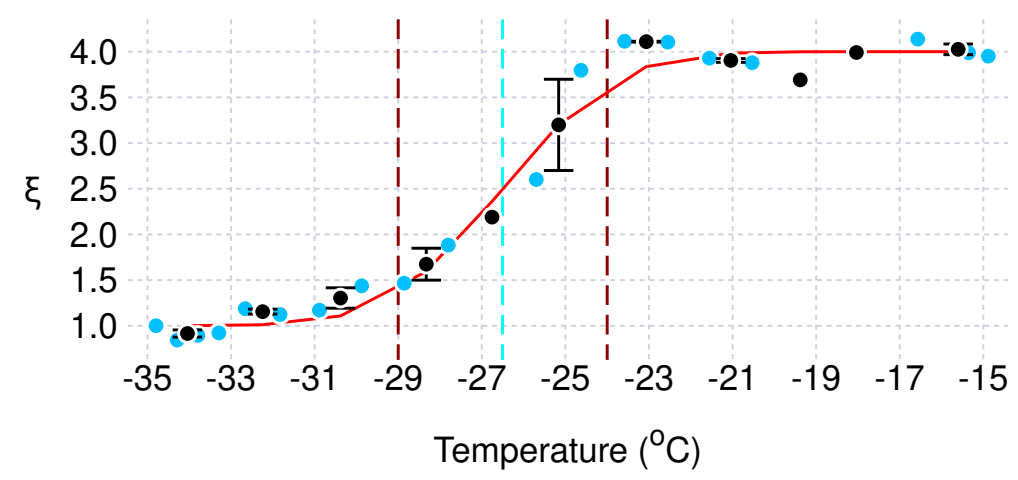

Figure S50. Particle shape parameter $\xi$ versus temperature 


\subsubsection{2_20190529S24:}

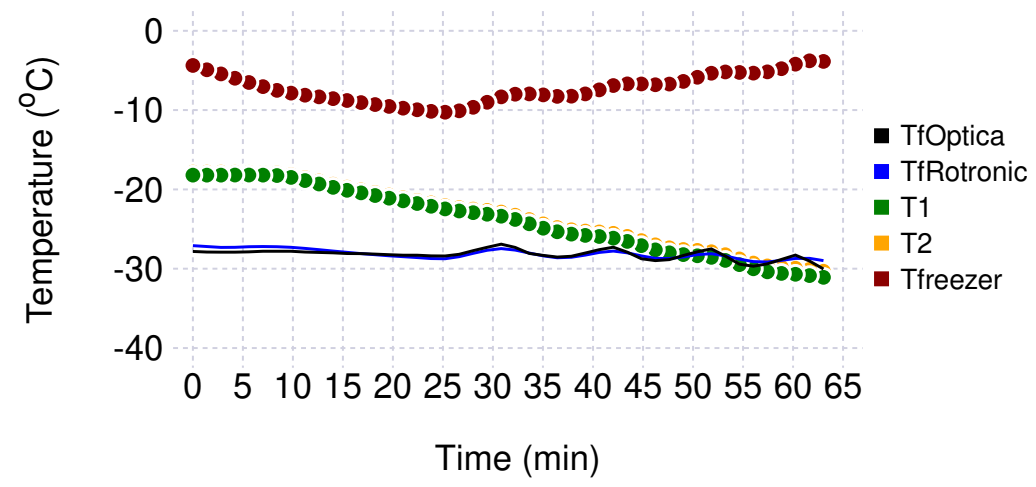

Figure S51. Variation of absolute temperatures and frost point temperatures over the duration of the experiment.

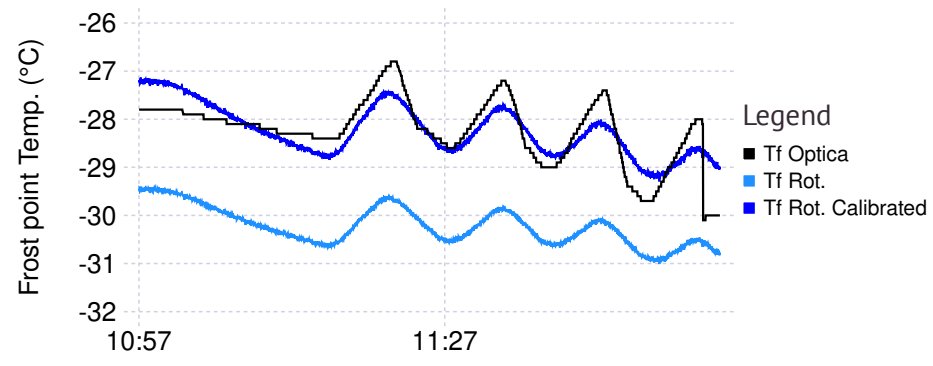

Time (HH:MM)
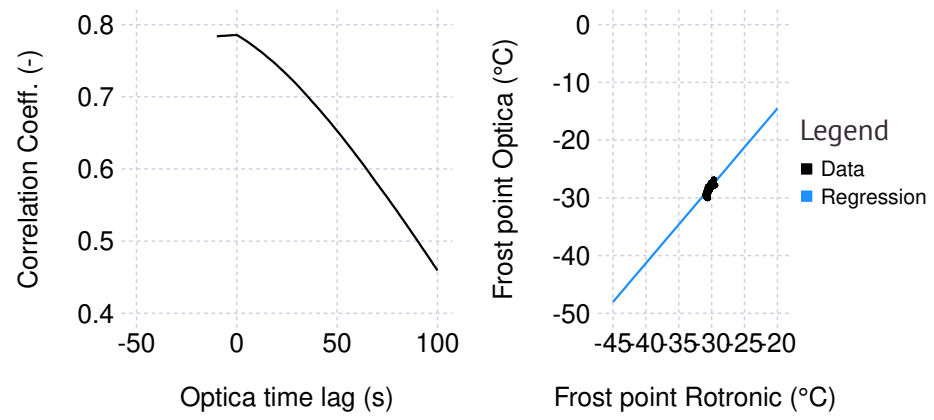

Figure S52. Calibration of RH sensors. 

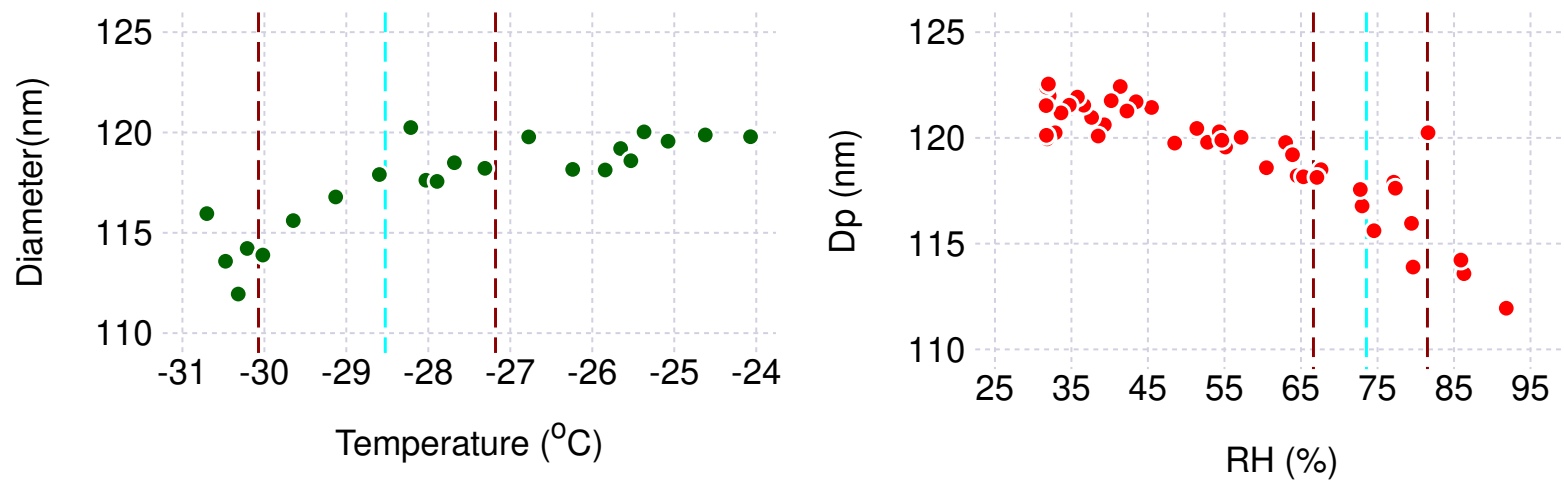

Figure S53. Evolution of the measured SMPS mode diameter versus temperature (left) and RH (right) for the ramp.

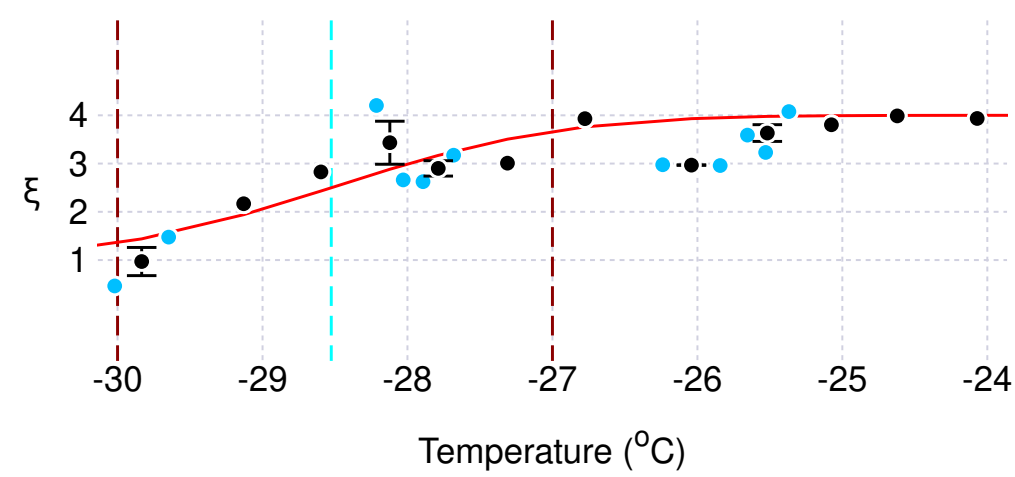

Figure S54. Particle shape parameter $\xi$ versus temperature 
Elamin, A. A., Sebhatu, T., and Ahlneck, C.: The Use of Amorphous Model Substances to Study Mechanically Activated Materials in the Solid State, International Journal of Pharmaceutics, 119, 25-36, https://doi.org/10.1016/0378-5173(94)00364-B, 1995.

Gordon, M. and Taylor, J. S.: Ideal Copolymers and the Second-Order Transitions of Synthetic Rubbers. i. Non-Crystalline Copolymers, Journal of Applied Chemistry, 2, 493-500, https://doi.org/10.1002/jctb.5010020901, 1952.

Jansson, H., Bergman, R., and Swenson, J.: Dynamics of Sugar Solutions as Studied by Dielectric Spectroscopy, Journal of Non-Crystalline Solids, 351, 2858-2863, https://doi.org/10.1016/j.jnoncrysol.2005.04.086, 2005.

Lienhard, D. M., Bones, D. L., Zuend, A., Krieger, U. K., Reid, J. P., and Peter, T.: Measurements of Thermodynamic and Optical Properties of Selected Aqueous Organic and Organic-Inorganic Mixtures of Atmospheric Relevance, The Journal of Physical Chemistry A, 116, 9954-9968, https://doi.org/10.1021/jp3055872, 2012.

Lu, Q. and Zografi, G.: Properties of Citric Acid at the Glass Transition, Journal of Pharmaceutical Sciences, 86, 1374-1378, https://doi.org/10.1021/js970157y, 1997.

Maltini, E. and Anese, M.: Evaluation of Viscosities of Amorphous Phases in Partially Frozen Systems by WLF Kinetics and Glass Transition Temperatures, Food Research International, 28, 367-372, https://doi.org/10.1016/0963-9969(95)00006-8, 1995.

Marsh, A., Petters, S. S., Rothfuss, N. E., Rovelli, G., Song, Y. C., Reid, J. P., and Petters, M. D.: Amorphous Phase State Diagrams and Viscosity of Ternary Aqueous Organic/Organic and Inorganic/Organic Mixtures, Phys. Chem. Chem. Phys., 20, 15086-15097, https://doi.org/10.1039/C8CP00760H, 2018.

Murray, B. J.: Inhibition of Ice Crystallisation in Highly Viscous Aqueous Organic Acid Droplets, Atmospheric Chemistry and Physics, 8, 5423-5433, https://doi.org/10.5194/acp-8-5423-2008, 2008.

Pokluda, O., Bellehumeur, C. T., and Vlachopoulos, J.: Modification of Frenkel's Model for Sintering, AIChE Journal, 43, 3253-3256, https://doi.org/10.1002/aic.690431213, 1997.

Rothfuss, N. E. and Petters, M. D.: Coalescence-Based Assessment of Aerosol Phase State Using Dimers Prepared through a Dual-Differential Mobility Analyzer Technique, Aerosol Science and Technology, 50, 1294-1305, https://doi.org/10.1080/02786826.2016.1221050, 2016.

Rothfuss, N. E. and Petters, M. D.: Characterization of the Temperature and Humidity-Dependent Phase Diagram of Amorphous Nanoscale Organic Aerosols, Phys. Chem. Chem. Phys., 19, 6532-6545, https://doi.org/10.1039/C6CP08593H, 2017.

Rothfuss, N. E., Petters, S. S., Champion, W. M., Grieshop, A. P., and Petters, M. D.: Characterization of a Dimer Preparation Method for Nanoscale Organic Aerosol, Aerosol Science and Technology, 39, 998-1011, https://doi.org/DOI: 10.1080/02786826.2019.1623379, 2019.

Saleki-Gerhardt, A. and Zografi, G.: Non-Isothermal and Isothermal Crystallization of Sucrose from the Amorphous State, Pharmaceutical Research, 11, 1166-1173, https://doi.org/10.1023/A:1018945117471, 1994.

Summers, M. and Enever, R.: Glass Transition Temperature of Citric Acid, Journal of Pharmaceutical Sciences, 69, 612-613, https://doi.org/10.1002/jps.2600690542, 1980.

Zobrist, B., Marcolli, C., Pedernera, D. A., and Koop, T.: Do Atmospheric Aerosols Form Glasses?, Atmospheric Chemistry and Physics, 8, 5221-5244, https://doi.org/10.5194/acp-8-5221-2008, 2008. 